\title{
Nucleus Basalis and Thalamic Control of Neocortical Activity in the Freely Moving Rat
}

\author{
György Buzsáki,, Reginald G. Bickford, Greg Ponomareff, Leon J. Thal, ${ }^{1}$ Ronald Mandel, and Fred H. Gage \\ Department of Neurosciences, University of California at San Diego, and 'Department of Neurology, San Diego, VA \\ Medical Center, La Jolla, California 92093
}

\begin{abstract}
EEG and single-unit techniques have been used to study the EEG correlates of cellular firing in the neocortex, $n$. reticularis (RT) and "specific" thalamic nuclei, and the cholinergic forebrain area (nucleus basalis, NB). Neuronal firing was related to the ongoing behavior of the rat. In addition, using a 16-channel neocortical recording/mapping system, we studied the effects of ibotenic acid lesion of NB, RT, and other thalamic nuclei on the patterns and spatial distribution of neocortical electrical activity. The majority of neurons in neocortex, NB, and RT increased their firing rates during walking, as compared to during immobility, with concurrent decrease of delta power in the neocortical EEG. During immobility, high-voltage spindles (HVS; $>1 \mathrm{mV}$ ) were occasionally recorded from the neocortex. Depth profiles of HVS and slow delta waves were different in the neocortex. Neocortical cells decreased their discharge frequency during the positive portion of delta waves recorded in layers $V$ and Vl. All cells in the neocortex and specific thalamic nuclei fired rhythmically and phase-locked to the spike component of HVS. RT neurons showed an opposite phase relationship and fired mainly during the wave component of HVS. Half of the NB neurons also showed phasic modulation with HVS. Circumscribed lesion of RT and extensive damage of other thalamic regions, including the intralaminar nuclei, suppressed HVS but had no effect on the neocortical EEG correlates of behavior. In sharp contrast, damage to the NB resulted in a dramatic increase of slow delta waves on the side of the lesion, mimicking the effect of scopolamine administration.
\end{abstract}

We suggest that the NB plays a key role in neocortical arousal by directly activating the neocortex and by suppressing the rhythm generation in the RT-thalamocortical circuitry. We further suggest that the NB system may serve as a structural basis for the concept of the generalized ascending activation of Moruzzi and Magoun (1949).

\footnotetext{
Received Nov. 13, 1987; revised Feb. 1, 1988; accepted Feb. 18, 1988.

We thank Drs. M. Steriade, L. J. Ryan, and C. H. Vanderwolf for their helpful comments on the manuscript, Jan Berglund and Steve Forbes for their expert technical assistance, and Sheryl Christenson for typing the manuscript. This work was supported by J. D. French Foundation for Alzheimer's Disease, California State Grant (86-89619), the VA Research Service, NIA Grant AGO6088, Office of Naval Research, and the Margaret and Herbert Hoover Foundation.

Correspondence should be addressed to G. Buzsaki, Department of Neurosciences, M-024, UCSD, La Jolla, CA 92093.

Copyright (C) 1988 Society for Neuroscience $0270-6474 / 88 / 114007-20 \$ 02.00 / 0$
}

One of the most influential and seminal principles regarding the mechanisms of the central nervous system was set forth by Moruzzi and Magoun (1949) with the formulation of the concept of the ascending reticular activating system to the neocortex. They hypothesized the existence of a nonspecific excitatory, energizing system that provided for the neocortex a "readiness" state for processing spccific afferent information. Their concept assumed a unitary control of the electrical activity of the cortex related to consciousness, arousal, and the sleep-waking cycle. The neuronal substrate of the hypothesized energizing system, however, has been a long-standing puzzle.

For the past 4 decades, it was generally accepted that the reticulothalamic system served the structural basis of neocortical activation. A subset of neurons in the brain-stem reticular formation was suggested as exciting the reticular nucleus (RT; Jasper, 1949; Papez, 1956; Rossi and Zanchetti, 1957) and later the intralaminar nuclei of the thalamus (Steriade, 1970); in turn, a diffuse projection from these nuclei to cerebral cortex was thought to represent the final common pathway of the ascending reticular activating system. This general scheme was supported by experiments showing that (1) stimulation of the brain stem reticular formation produced arousal-related EEG desynchronization (Moruzzi and Magoun, 1949) and facilitated transmission through the thalamocortical system (Steriade, 1970; Singer, 1977), (2) systemic injection of the cholinolytic drug atropine blocked arousal-associated neocortical desynchronization (Wikler, 1952; Herz, 1959), and (3) that an AChE-rich projection originated from the brain stem and extended to or through the thalamus (Shute and Lewis, 1967).

Experimental data accumulated over the last several years indicate, however, that there is no projection from the RT to the cerebral cortex (Jones, 1985), and that the RT may play a crucial role in neocortical rhythmic synchronization and not activation-related desynchronization (Steriade and Deschênes, 1984; Steriade et al., 1985, 1987). Thus, the essential circuitry of the activating concept, i.e., an excitatory reticulothalamic path coupled with a widespread diffuse thalamocortical system, has been reduced to the intralaminar nuclei of the thalamus (Steriade, 1970). The number of other subcortical candidate structures with the required global neocortical innervation is few; the major contenders include the basal forebrain nuclei (Divac, 1975; Lehmann et al., 1980; Saper, 1984), the dorsal raphe nuclei (Moore et al., 1978), the locus coeruleus (Lindvall et al., 1974), and the ventromedial thalamic nucleus (Herkenham, 1979).

In the behaving animal, the typical electrical activity is characterized by low-voltage fast waves (LVF, desynchronized or arousal pattern). In the drowsy or sleeping animal, large-am- 
plitude slow waves (synchronized) are observed in the delta band (1-4 Hz) (Longo, 1966; Vanderwolf, 1975). Furthermore, in the motionless but awake rat, a highly synchronized EEG pattern, characterized by large-amplitude rhythmic waves in the theta/ alpha band (6-12 Hz, high-voltage spindles, HVS), has been described by Gottesmann (1967) and Klingberg and Pickenhain (1968).

$\Lambda$ basic question concerning the physiology of the ccrcbral cortex involves the activating afferents that keep the neocortex in the waking state. A cholinergic activating input has long been implicated because administration of antimuscarinic drugs, such as atropine or scopolamine, results in slow delta waves, and, under the effect of atropine, physiological sensory stimuli no longer have a sufficient "activating" or "desynchronizing" effect on the cortical electrical activity (Wikler, 1952; Нerz, 1959; Longo, 1966). It was noticed early on, however, that the "dissociation" (Wikler, 1952) between cortical EEG and behavior was not absolute, since the delta wave-producing ability of the antimuscarinic drugs depended on the performance of the animal (Sadowski and Longo, 1962; Vanderwolf, 1975; Vanderwolf and Robinson, 1981). Vanderwolf (1975) and colleagues (Vanderwolf and Baker, 1986; Vanderwolf and Stewart, 1986) postulated that during exploratory behaviors (running, walking, rearing) the neocortex is activated by an atropine-resistant system, possibly serotoninergic.

Since the involvement of a cholinergic-muscarinergic activating input to the neocortex is now well documented, the question arises as to the origin of the cholinergic neurons responsible for the cortical arousal. The possible candidates are the numerous cholinergic cells intrinsic to the neocortex (Armstrong et al., 1983; Houser ct al., 1985), the cholinergic projection from the brain stem to the thalamus (Hallanger et al., 1987), and the major cholinergic afferent system to the neocortex, the basal forebrain (Divac, 1975; Jones et al., 1976; Mesulam and Van Hoesen, 1976).

The present quantitative studies were undertaken against the background of a growing awareness of the important role played by the cholinergic basal forebrain nuclei in Alzheimer's disease (Whitehouse et al., 1981; Bartus et al., 1982) and in the regulation of the sleep-wakefulness cycle (Sterman and Clemente, 1962; McGinty and Sterman, 1968).

To date, only 2 studies have examined the effect of destruction of the nucleus basalis/substantia innominata (NB) on neocortical EEG, and the results conflict. Lo Conte et al. (1982) reported that electrolytic lesions of the NB in the rat depressed the electrocortiogram. Stewart et al. (1984), using extensive kainic acid destruction of the NB, found increased dclta waves in the ipsilateral neocortex during immobility. Unfortunately, in this latter study NB lesions also produced extensive damage to the thalamus, and interpretation of their findings is difficult because of the documented distal cortical damage due to kainic acidinduced seizures (McGeer et al., 1983).

In the present study we investigated the correlation between cortical EEG and cellular activity in the neocortex, thalamus, and NB, and the depth profiles of delta waves and HVSs in the neocortex. We also studied the consequences of selective ibotenic acid lesions of the NB and RT and other thalamic nuclei on the neocortical electrical activity.

On the basis of our experiments, we conclude that the basal forebrain system, via its direct activation of the cerebral cortex and by suppressing the RT-thalamocortical-synchronizing circuitry, plays an essential role in neocortical activation.

\section{Materials and Methods}

Animals and surgery. The subjects of these experiments were 24 female Fischer 344 (2-15 month) and 42 female Sprague-Dawley (3-10 month) rats. Surgery was performed under deep anesthesia induced by a mixture $(4 \mathrm{ml} / \mathrm{kg})$ of ketamine $(25 \mathrm{mg} / \mathrm{ml})$, rompun $(1.3 \mathrm{mg} / \mathrm{ml})$, and acepromazine $(0.25 \mathrm{mg} / \mathrm{ml})$. The rat was placed in the stereotaxic apparatus with bregma and lambda in the same horizontal plane. For mapping studies, 18 holes were drilled in the skull using a prefabricated plexiglass template at the following coordinates: $\mathrm{L}=2.5, \mathrm{AP}$, relative to bregma $=2.5,0.0,-2.5,-5.0,-7.5 ; \mathrm{L}=5.0, \mathrm{AP}=0.0,-2.5,-5.0$. Selftapping gold-plated stainless steel screws $(0.5 \mathrm{~mm}$ in diameter) were driven into the skull so that the tip just reached the dura. Sixteen served as active recording electrodes relative to a different screw electrode (indifferent) placed in the midline above the cerebellum. The last screw served to ground the rat (Fig. 1). The electrodes and connected male pins were embedded in dental acrylic. In 12 animals, bipolar recording electrodes (stainless steel Formvar-insulated wires, $120 \mu \mathrm{m}$ in diameter) were implanted in 8 holes over the right hemisphere, using the same coordinates described above. One electrode tip lay on the surface of the dura, while the deeper tip penetrated $1.0 \mathrm{~mm}$ below the surface of the cortex. In this latter group, signals were recorded both bipolarly (surface to depth) and monopolarly (surface to indifferent). Four 4-channcl Mosfet input operational amplifiers mounted in the female connector served to eliminate cable movement artifacts. In animals with ibotenic acid lesions of the NB, RT, or other thalamic nuclei, a hole was made in the skull above the target area and left free in the course of the preparation of the acrylic headstage. Following baseline recordings, the rat was reanesthetized and placed in the stereotaxic instrument. A volume of 1.0 $3.0 \mu \mathrm{l}(1.0 \mu \mathrm{g}$ ibotenic acid/1 $\mu \mathrm{l}$ PBS; $\mathrm{pH}$ 6.5-7.4) was infused into the thalamus and $1 \mu$ into the NB over a $5-15$ min period.

In 6 rats the NB was lesioned on both sides, with 1 week recovery between left and right hemisphere lesions in order to avoid aphagia and adipsia. In experiments using microelectrode penetration, a $4.0-\mathrm{mm}$ diameter hole was drilled into the skull (centered $\mathrm{AP}=-0.8, \mathrm{~L}=3.0$ for NB; $\mathrm{AP}=-2.0, \mathrm{~L}=0.5-3.0$ for $\mathrm{RT}$ and other thalamic nuclei) and a nylon cylinder $(5.0 \mathrm{~mm}$ I.D.) was cemented to the skull to serve as a receptacle for the microdrive. One turn of the microdrive moved the tungsten electrode $(0.5-10 \mathrm{M} \Omega$ ) by $210 \mu \mathrm{m}$. A bipolar wire-stimulating electrode was implanted into the neocortex contralaterally to the microdrive ( $\mathrm{AP}=-2.0, \mathrm{~L}=3.0$ ) or ipsilaterally right behind the microdrive socket. Four screw electrodes, 2 on each side $(\mathrm{AP}=2.0, \mathrm{~L}=3.0$; $\mathrm{AP}=-6.0, \mathrm{~L}=3.0$ ), were also implanted in the skull. Recordings were made differentially against the indifferent electrode above the cerebellum.

Five newborn rats were anesthetized with ether and hypothermia Following exposure of the skull, cuts were made parallel to the sagittal, coronal, and lambdoidal sutures with microscissors. The skull was unfolded and, under a surgical microscope, the dorsal part of the neocortex and hippocampus was removed by aspiration. At 7 months of age, the rats were implanted with electrodes as described above.

Behavioral training. Following surgery, the rats were trained to run in a wheel $(30 \mathrm{~cm}$ in diameter) for a water reward, as described earlier (Buzsáki et al., 1983). The wheel was attached to a box $(40 \times 40 \times 40$ $\mathrm{cm}$ ). Opposite the wheel, a drinking tube protruded into the box. After a predetermined number of revolutions of the wheel, the availability of a water reward $(0.2 \mathrm{ml})$ was signaled by a tone stimulus $(2000 \mathrm{~Hz})$. Some animals were simply placed in the apparatus and recordings were made during spontaneous behaviors such as walking, sitting still, lying, and sleep posture.

Recording, stimulation, and data processing. Bioelectric activity was amplified and filtered $(1-70 \mathrm{~Hz}$ for EEG, $1 \mathrm{~Hz}-5 \mathrm{kHz}$ for evoked potentials, and $0.5-5 \mathrm{kHz}$ for unit activity), recorded on a polygraph (Grass 8-18D), and stored on hard disk. Unit discharges were discriminated by a window discriminator (WPI) and a softwarc program (R. C. Electronics).

With the exception of averaging evoked field responses, the data were analyzed off-line. The sampling frequency was $128 \mathrm{~Hz}$ for EEG. Power was estimated for periods of $20 \mathrm{sec}$ by averaging five $4 \mathrm{sec}$ short-time spectra obtained during identical behaviors. Numerical values were obtained for the delta $(0-4 \mathrm{~Hz})$, theta $(4-8 \mathrm{~Hz})$, alpha $(8-12 \mathrm{~Hz})$, and beta $(12-20 \mathrm{~Hz})$ bands. These bin values were used to construct 2-dimensional surface EEG maps with a LSI 11/40-based minicomputer (Minicears; Bickford, 1981; Bickford and Allen, 1986). Temporal crosscorrelation between field potentials from different cortical regions and 

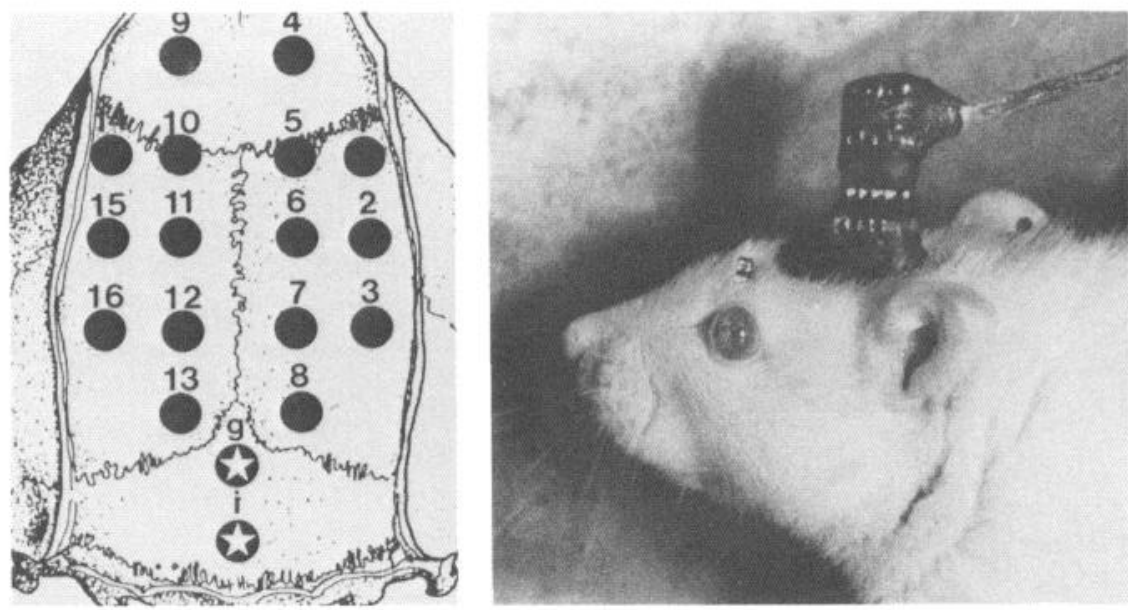

Figure 1. Schematic and numbering of electrode locations. $g$, Ground; $i$, reference electrode. Right, headstage with the compact 16-channel Mosfet preamplifier system. between surface and depth potentials was assessed by wave-aspect averaging using a waveform-recognition program ( $R$. C. Electronics). The same method was used to evaluate the relationship between field potentials and cellular discharges (Buzsáki, 1986). The numerical data were evaluated by analyses of variance (ANOVA), Student's $t$ test, or the nonparametric Mann-Whitney tests.

Histology. Following the last microelectrode penetration, the microelectrode was left in the brain and the rats were perfused transcardially with $100 \mathrm{ml}$ PBS, followed by $400 \mathrm{ml}$ ice-cold $4 \%$ buffered paraformaldehyde. The brains were postfixed in the same solution and then immersed in $30 \%$ sucrose. Serial sections $(30 \mu \mathrm{m})$ were cut and neigh- boring sections were stained for AChE (Koelle, 1956), for CAT (Armstrong et al., 1986), and for cresyl violet.

\section{Results}

Effect of behavior and scopolamine on neocortical EEG

Raw neocortical EEG records obtained during various behaviors are shown in Figure 2. With the exception of immobility periods with HVS, the electrical activity consisted of irregular low-voltage fast activity. The subtle behavior-related changes in the
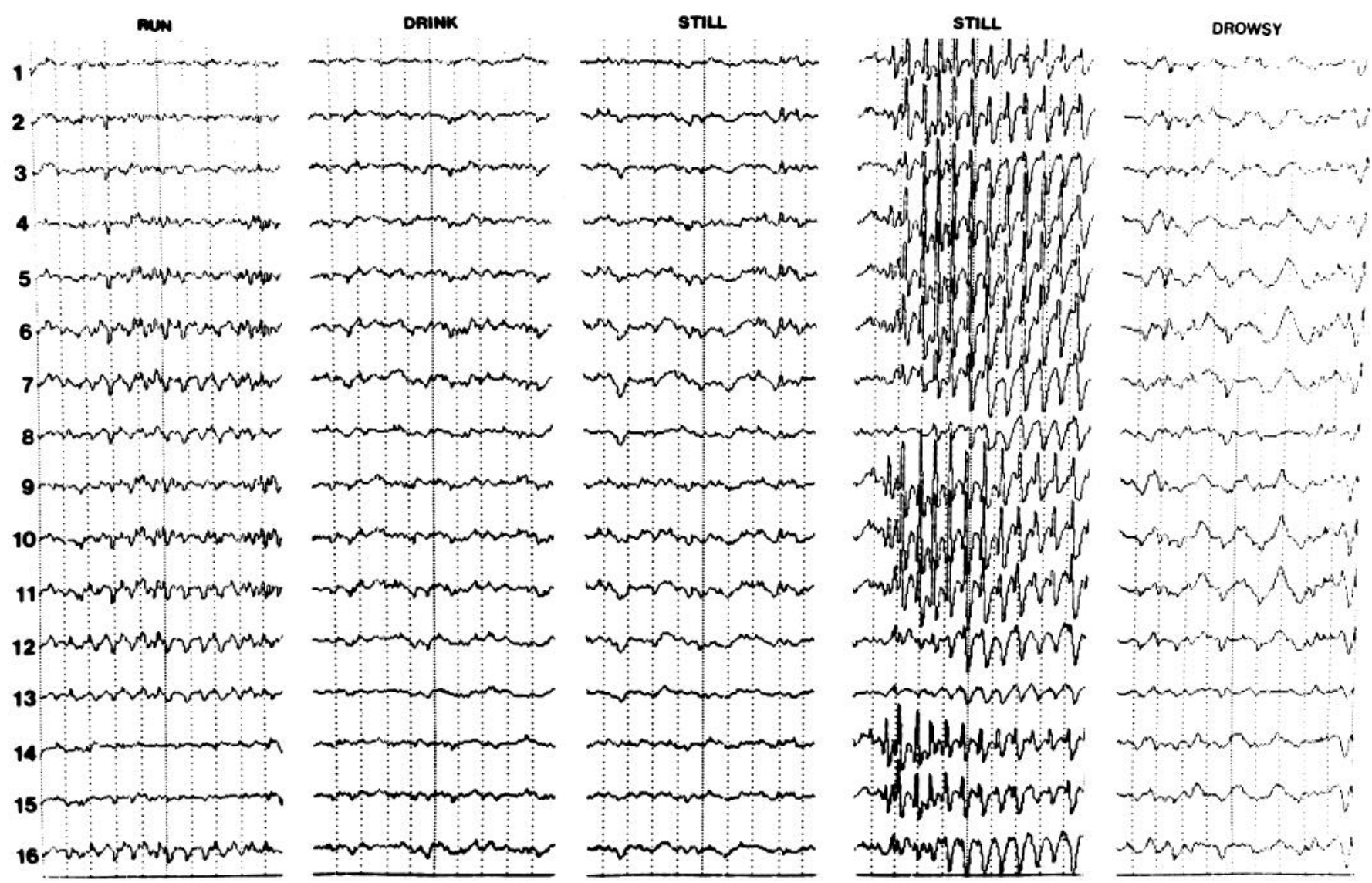

Figure 2. Patterns of neocortical EEG during different behaviors ( $2 \mathrm{sec}$ segments). Derivations $1-16$ correspond to locations shown in Figure 1 . Rhythmic waves at theta frequency during running may have been volume-conducted from the hippocampus. Calibration, $1 \mathrm{mV}$. 


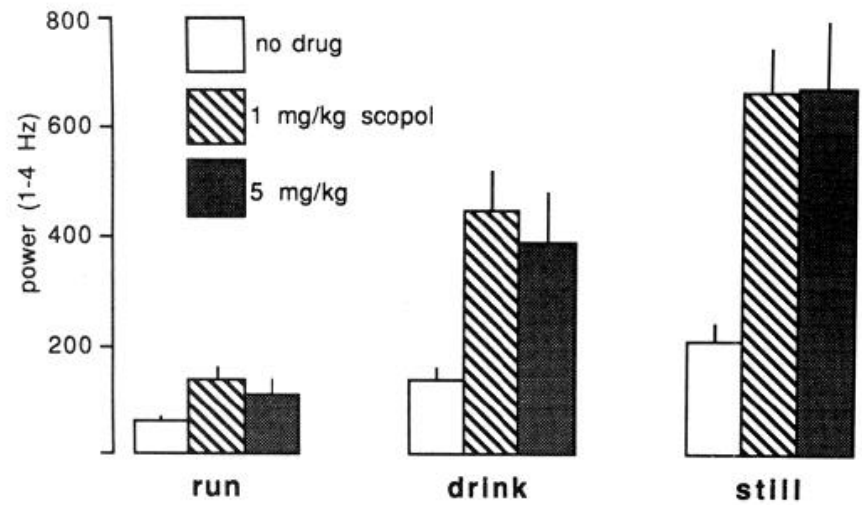

Figure 3. Spectral power in the delta band $(1-4 \mathrm{~Hz})$ during run-drinkstill transitions. Bipolar recording at location 6 of Figure 1 ( $n=12$ rats). Note monotonic increase in power from run to still. Note also that scopolamine-induced power increase is disproportionally greater during sitting still than during running. The 2 doses of scopolamine were tested in the same animals. Vertical bars, SEM. Arbitrary units.

electrical patterns were difficult to describe qualitatively. Quantitative analysis of the power spectra revealed, however, that the power of slow waves $(1-4 \mathrm{~Hz})$ increased monotonically during run-drink-immobility transitions $(F=19.79, p<0.001)$ (Fig. 3).

Although scopolamine- $\mathrm{HBr}$ affected the neocortical EEG during all behaviors (Fig. 3; $F=68.88, p<0.001$ ), its effect was more pronounced during immobility and drinking, as revealed by a highly significant behavior $\times$ treatment interaction $(F=$ $7.89, p<0.001)$. A dose of $0.2 \mathrm{mg} / \mathrm{kg}$ produced a large effect, and no further changes were observed above $1.0 \mathrm{mg} / \mathrm{kg}$.
High-voltage spindles (HVSs)

An episode of HVS during immobility is shown in Figure 2. HVSs were observed in every rat on at least one occasion. In a group of 11 rats, the EEG was recorded in 2 or 3 sessions, each involving $30 \mathrm{~min}$ cumulative periods of immobility. The average frequency of HVS was $2.3 / 30 \mathrm{~min}$ (range, 1-7). For a HVS to occur, the rat had to be immobile for at least $5-10 \mathrm{sec}$. The HVS typically began with spike-and-wave patterns; this was followed by spikes and waves only during a long HVS episode. The amplitude of the spike component, recorded by epidural screw electrodes, could exceed $1.0 \mathrm{mV}$. The duration of the HVS varied from 0.5 to $10 \mathrm{sec}$. The intraspindle frequency was usually highest at the onset of the HVS $(8-10 \mathrm{~Hz})$, with a gradual deceleration to $6-8 \mathrm{~Hz}$ by the end of the spindle episode.

The most striking feature of the HVS was its highly synchronous nature over both cerebral hemispheres (Fig. 2). The largestamplitude HVSs were recorded over the posterofrontal-parietal regions while the spike amplitude decreased rapidly toward the occipital region. HVSs were recorded only when the rat was sitting motionless with eyes open. Occasionally, rhythmic tremor of vibrissae at HVS frequency was present during an HVS episode. The HVS arose from a desynchronized background. The presence of large-amplitude slow waves during drowsiness decreased the probability of occurrence of HVS.

Small doses of scopolamine $(0.2 \mathrm{mg} / \mathrm{kg})$ resulted in a $3-4$-fold increase in the incidence of HVS. However, HVS episodes registered under the effect of scopolamine were very short, consisting of a series of 3-6 spikes and waves.

Single-pulse $(0.1 \mathrm{msec}, 80-300 \mu \mathrm{A})$ stimulation of the neocortex could reliably evoke HVSs. However, stimulation was
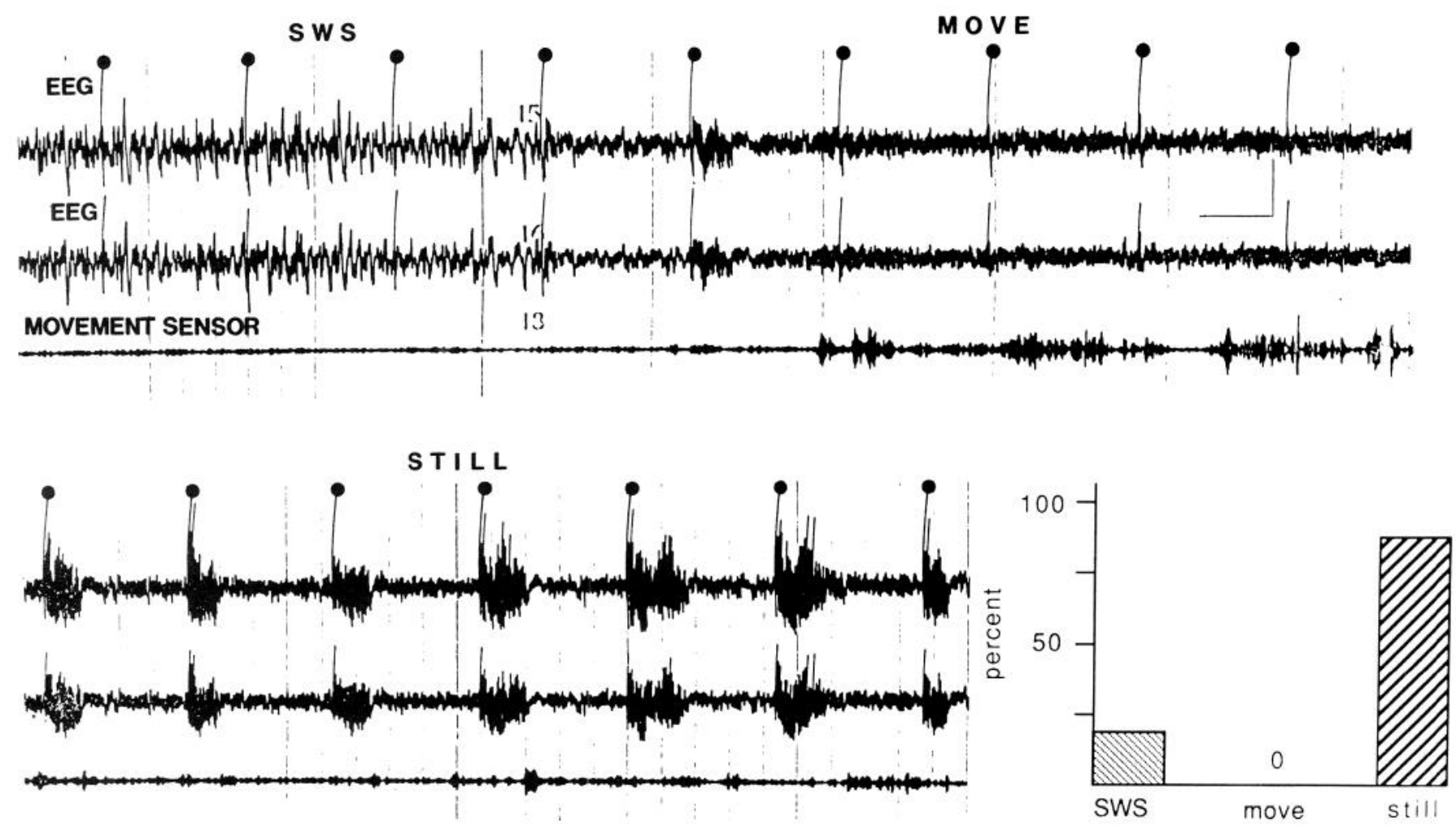

Figure 4. Neocortically triggered HVSs. Dots indicate single-pulse $(0.1 \mathrm{msec})$ stimulation of the neocortex (location 2 in Fig. 1$)$. Note the frequent occurrence of induced HVS during sitting still $(S T I L L)$ and its absence during slow-wave sleep $(S W S)$ and movement $(M O V E)$. The graphs on the right are based on 30 stimulations each. The sensitivity of the movement sensor was doubled during still behavior. Calibrations, 5 sec, $1 \mathrm{mV}$. 

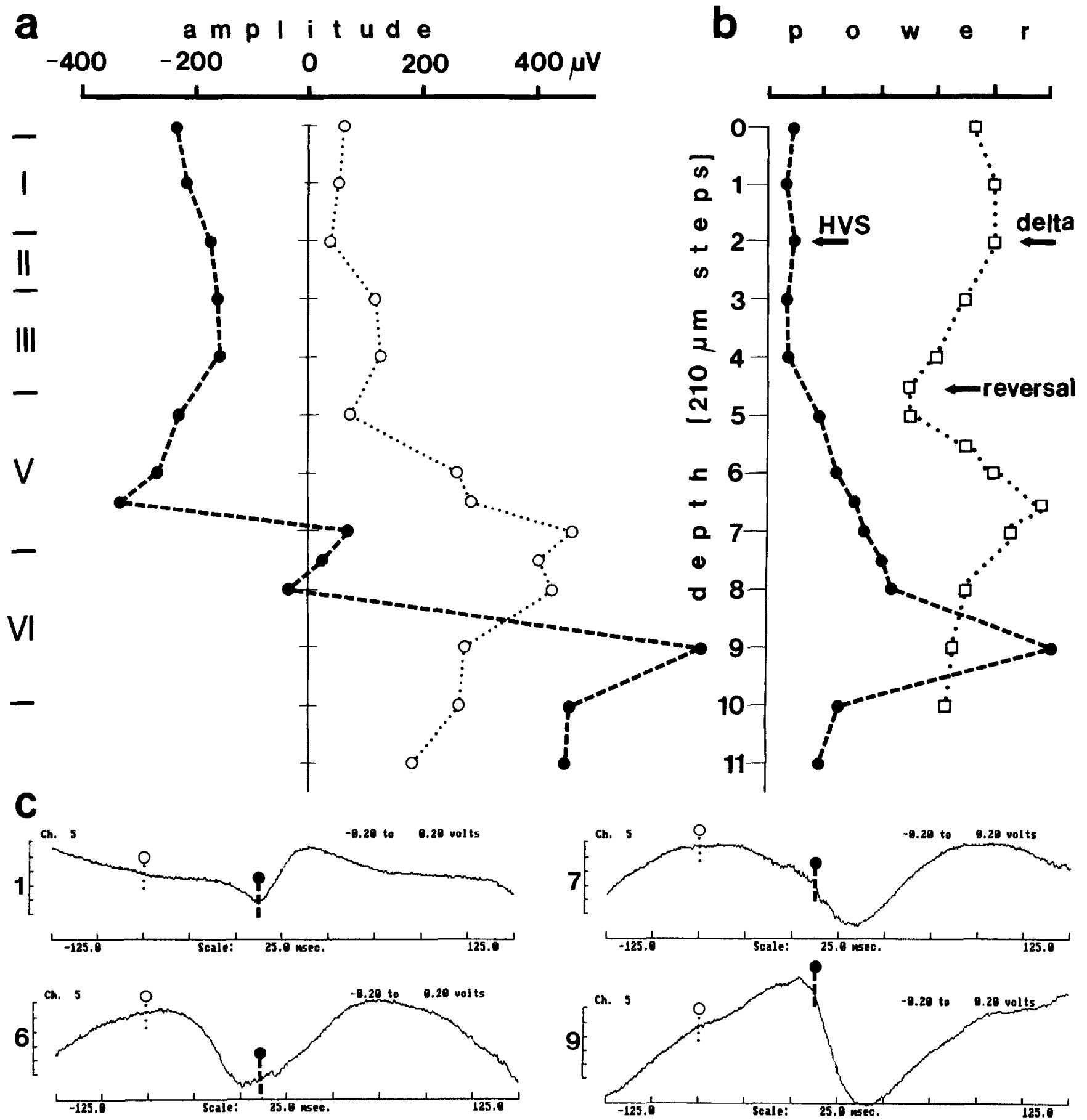

Figure 5. Depth profiles of HVS and delta waves. a, Amplitude distribution of the spike (interrupted line, black dots) and wave (dotted line, circles) components of HVS as a function of depth. Samples of averaged HVSs $(n=30)$ at various depth levels are shown in $c . b$, Laminar distribution of the power of HVS $(4-8 \mathrm{~Hz}$, black dots) and delta waves $(1-4 \mathrm{~Hz})$ during drowsy state. The amplitude $(a)$ and power $(b)$ units were normalized by dividing the values obtained from the roving microelectrode by the values obtained from a cortical screw electrode and multiplying the ratio by the grand average. Note different depth profiles of HVS and delta waves.

effective only during immobility periods, when HVSs also occurred spontaneously. During movement, stimulation was ineffective even at high-intensity levels (Fig. 4). Loud acoustic stimuli, picking up the animal, or tapping the wall of the experimental chamber, but not weaker stimuli, abruptly terminated an ongoing HVS. When click stimuli were randomly presented at a $0.02-0.2 / \mathrm{sec}$ rate during HVSs, no evoked cortical activity could be observed. This finding suggests that input to the neocortex is strongly suppressed during HVS.

\section{Depth profiles of slow waves and HVS}

In an attempt to reveal whether HVS and the slow delta waves are produced by identical or by different sets of synapses, we carried out depth profile measurements of these waves in 10 rats.

Slow delta waves $(1-4 \mathrm{~Hz})$ displayed an abrupt reversal of phase at the upper border of layer V. Maximum power was observed in layer $\mathrm{V}$ and in the upper layers. Between the upper 


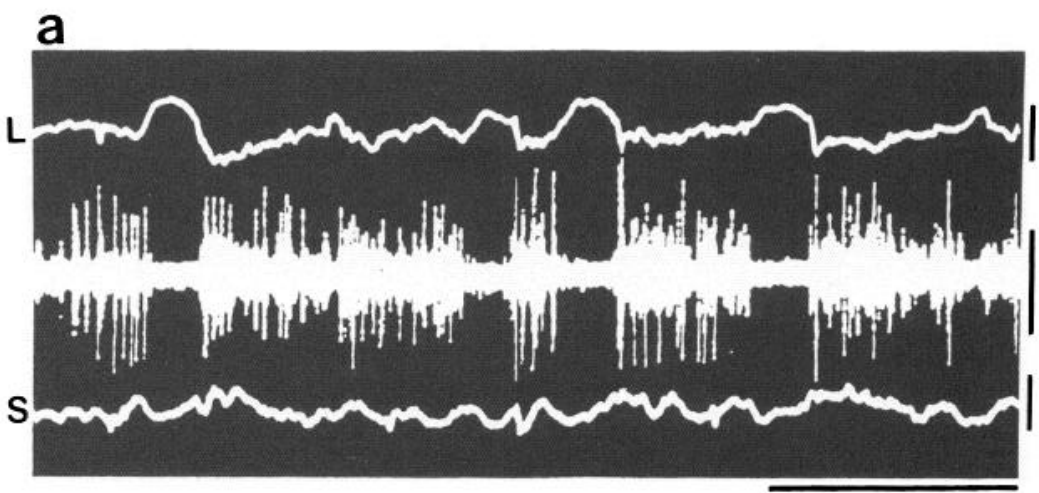

Figure 6. Relationship between slow waves (delta) and cellular activity in the neocortex. $a$, Multiple-unit recording in layer V. $b$, Single unit in layer V. Note opposite polarity of slow waves in layer $\mathrm{V}(L)$ and surface $(S)$ and suppression of firing during local positivity. $c$, Same cell as in $b$, showing orthodromic activation by stimulating the contralateral neocortex. Dots, spontaneous and evoked unit discharges. White arrow, antidromically evoked population spike. Calibrations: $1 \sec (a, b) ; 10 \mathrm{msec}(c)$; $1 \mathrm{mV}$ (field); $0.2 \mathrm{mV}$ (unit) b

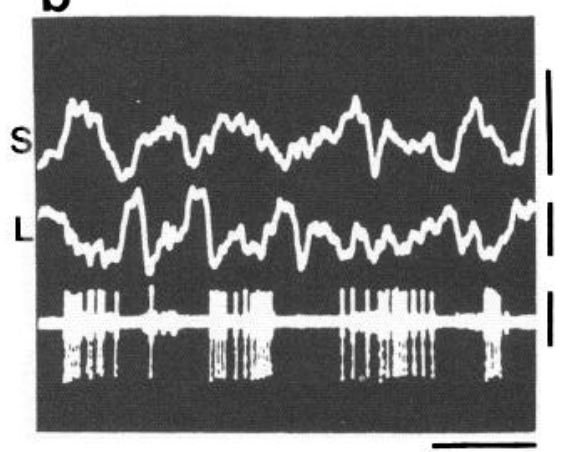

$\mathrm{cl}$

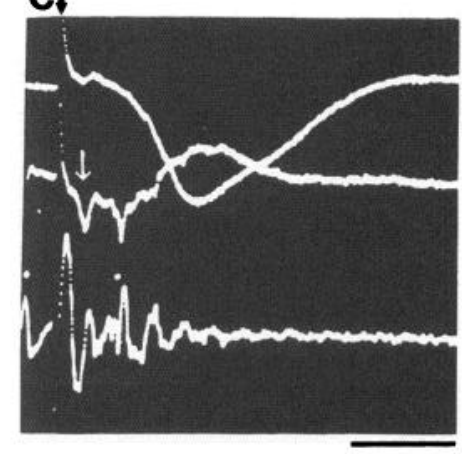

and lower power maxima, a zone of minimum amplitudes, coinciding with the depth of phase-reversal, was observed (Fig. $5)$.

The wave component of HVS displayed a depth distribution similar to that of the delta waves. In contrast, the spike component of HVS showed no steep reversal of phase. Instead, a gradual shift of the spike component was evident in all animals (Fig. 5). The spike component was negative in the upper layers and positive only in layer $\mathrm{V}$ and below. The "null" zone of the polarity transition of the spike component corresponded to the amplitude maximum of the wave component. The wave component remained positive throughout all cortical layers.

\section{Relationship between EEG and cellular activity}

Neocortex. During drowsy states, large-amplitude slow delta waves were apparent in both the surface and depth records. A clear relationship was present between EEG waves and both multiple- and single-unit firing. During the negative portion of the surface waves, unitary activity typically decreased at all depths. This relationship was most apparent in layers $\mathrm{V}$ and VI, where virtually no cell firing was present during the positive portion of the local waves (Fig. 6). Five neurons were tentatively classified as local circuit neurons, based on (1) repetitive and high-frequency discharge evoked by single-pulse stimulation of the contralateral somatomotor cortex and (2) high spontaneous discharge rates $(>10 \mathrm{~Hz})$ when motionless (Lynch, 1980). These putative local circuit neurons also decreased their discharge frequency during large surface-negative, depth-positive waves.

Multiple-unit recordings with low-impedance $(<1 \mathrm{M} \Omega)$ electrodes showed dramatic changes of neuronal activity during a HVS episode. Typically, large-amplitude bursts of rhythmic cell discharges occurred in concurrence with the spike components of the HVS, and the amplitude of the multiple-unit recording channel fell to the electronic noise level of the amplifying system between the spike components of HVS, indicating the absence of action potentials during the wave component of HVS. These observations were confirmed by single-unit recording data.

Ninety-two cells were isolated and held for a sufficient time to study the relationship between HVS and single-cell firing. All neocortical cells fired in synchrony with the spike component of the HVS (Fig. 7). Twenty of these cells met the criteria of antidromic firing from the contralateral hemisphere, including collision (Lipski, 1981). Putative local circuit neurons also fired almost exclusively during the spike component of HVS (Fig. 7, $a, b$ ).

Thalamus. Microelectrode penetrations were made through the ventrolateral, ventromedial, anteromedial, and RT nuclei. Similarly to the neocortex, background activity of cellular firing usually decreased for $2-5 \mathrm{sec}$ before the onset of HVS. With the exception of the cells in the anteromedial nucleus, all nuclei of the thalamus displayed rhythmic discharges in correlation with neocortical HVS. As the synchrony of the local neuronal population increased, rhythmic field potentials also emerged in the thalamus.

Neurons in the ventrolateral and ventromedial nuclei displayed a striking spike-pattern change during immobility-HVS transitions. These cells fired single spikes during running, drinking, and immobility. With the onset of HVS, however, most neurons displayed bursts of 2-7 spikes at $100-400 \mathrm{~Hz}$, concurrent with the spike component of HVS (Fig. 8). All cells encountered in these nuclei fired at or slightly preceded the peak of the spike component of HVS recorded from the surface of the neocortex.

The behavior of cells in RT was substantially different from 

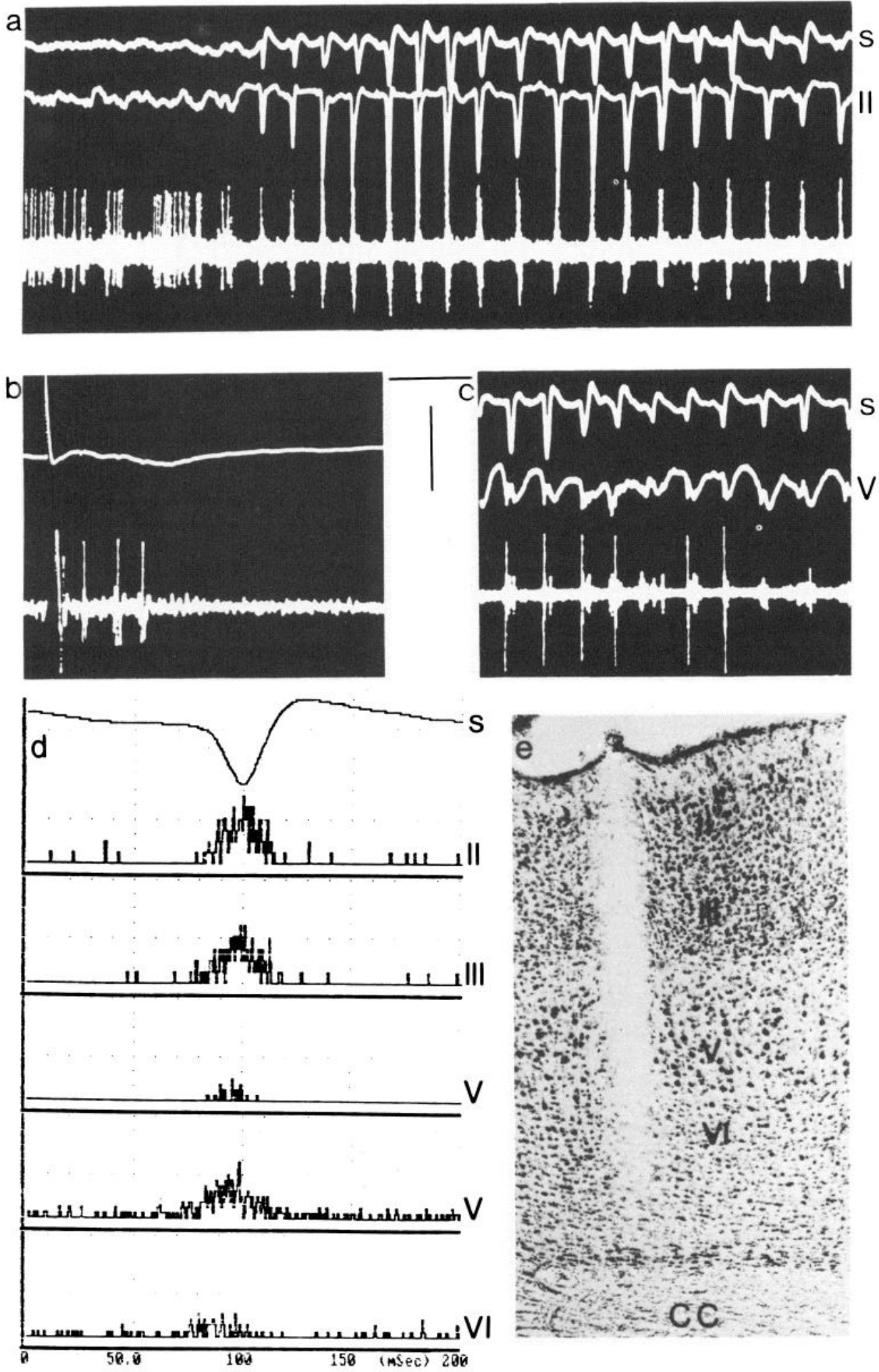

Figure 7. Relationship between neuronal firing and HVS in the neocortex. $a$, Activity of a layer II cell. $b$, Response of the neuron shown in $a$ to single-pulse stimulation of the contralateral homotopic area. $c$, Layer $\mathrm{V}$ cell. $s$, Surface recording; $I I(a), V(c)$, focal recording. $d$, Perievent histograms $(n=50)$ and averaged HVS from the cortical surface $(s)$. Neurons II-VI were recorded from the same track $(e) . c c$, Corpus callosum. Note synchrony of all cells with the spike component of HVS. Units II and upper $\mathrm{V}$ correspond to cells in $a$ and $c$, respectively. Calibrations: $1 \mathrm{mV}$ (field); $0.2 \mathrm{mV}(a, b) ; 0.5 \mathrm{mV}$ (c, unit); $0.4 \mathrm{sec}$ $(a, c) ; 20 \mathrm{msec}(b)$. Positivity up. that of other thalamic cells. Their average frequency also decreased during walk-immobility transitions. Four of the 17 cells recorded from RT showed rhythmic burst firing at $5-8 \mathrm{~Hz}$ during immobility or when the rat was sitting with slight head movements in the absence of HVS (Fig. 8a). At the onset of HVS the bursts became phase-locked to the wave component of HVS. This phase relationship was the same in those neurons that did not display rhythmicity in the absence of HVS. In response to stimulation of the ipsilateral neocortex, RT neurons fired with repetitive discharges of $2-15$ spikes (Fig. $8 c$; see also Schlag and Waszak, 1971; Steriade et al., 1986). In rats with the neocortex removed the pattern and frequency of cell discharges and locally recorded HVSs were similar to those of normal animals.

Nucleus basalis. Forty-nine cells in 8 rats were recorded from 

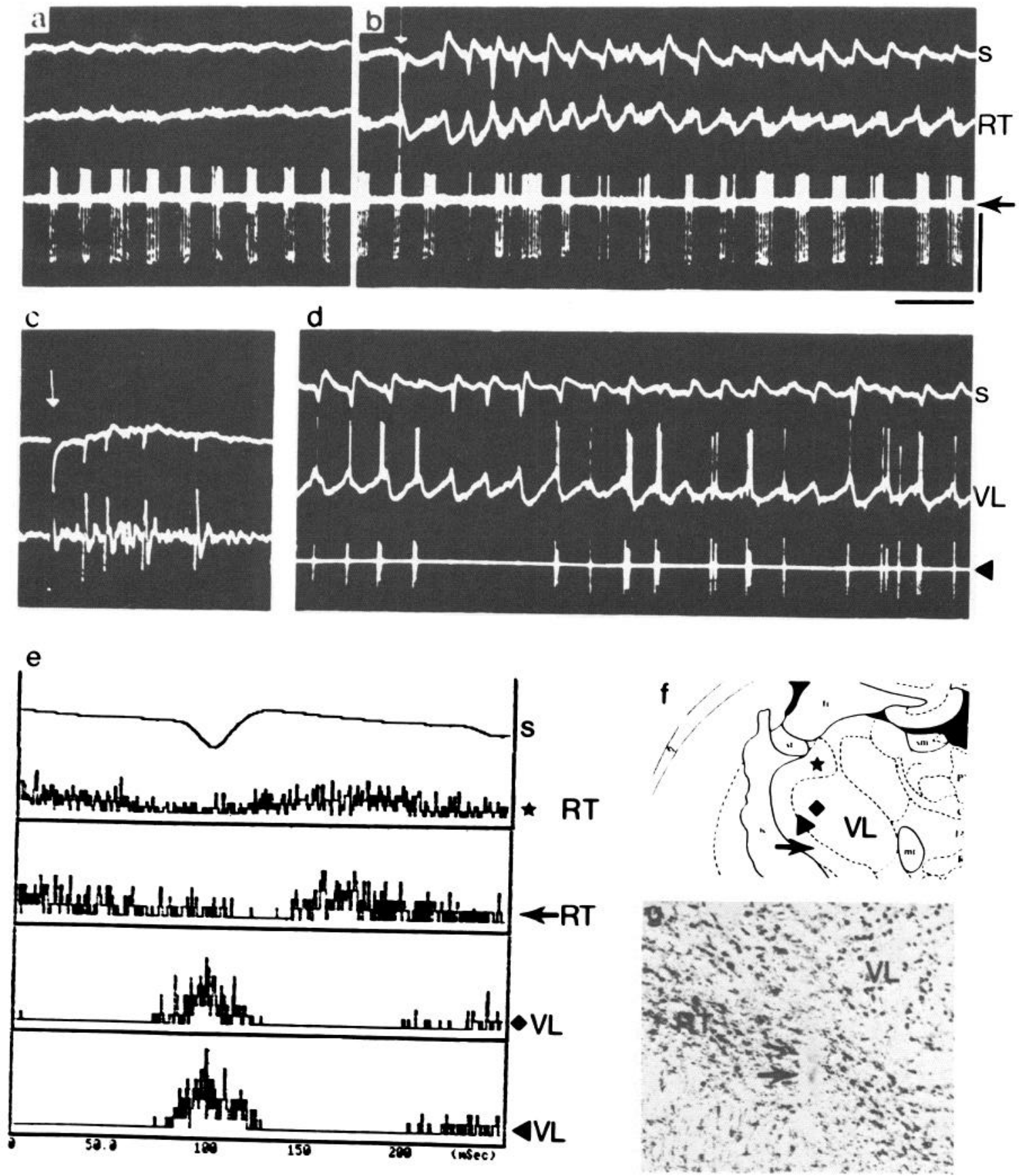

Figure 8. Neuronal activity of the thalamus during HVS. $a-c$, RT cell. $a$, Rhythmic firing $(6 \mathrm{~Hz})$ while sitting still in the absence of HVS. $b$, HVS evoked by single-pulse stimulation of the ipsilateral neocortex (arrow), $c$, Faster sweep speed. Note repetitive discharge. $d$, Unit in $\mathrm{n}$. ventralis lateralis $(V L)$. Note single and burst discharges during the spike component of HVS. $e$, Perievent histograms $(n=50)$ of 4 cells recorded in the same track $(f)$ and averaged HVS recorded from the neocortical surface $(s)$. Note opposite phase relationships of RT and VL cells in relation to HVS. Symbols in $f$ indicate the locations of the units shown in $a-e$. $g$, A small lesion (arrow) indicates the tip of the microelectrode in RT. Calibrations: $2 \mathrm{mV}$ (field); $0.2 \mathrm{mV}(a-c) ; 1 \mathrm{mV}(d$, unit); $0.4 \mathrm{sec}(a, b, d) ; 10 \mathrm{msec}(c)$.

the peripallidal region, substantia innominata, and the magnocellular preoptic nucleus. We could study the relationship between cell firing and behavior in 31 cells. In 25 neurons, the frequency of firing was substantially higher during walking (average, $18.5 / \mathrm{sec}$; range, $7-60 / \mathrm{sec}$ ) compared to during immobility (average, $8.2 / \mathrm{sec}$; range, $0.1-25 / \mathrm{sec}$ ). At the onset of HVS these neurons showed a further decrease of their discharge rates (Fig. $9 a$ ). Only 2 cells showed the opposite relationship, i.e., increased firing during immobility and the drowsy state. One of them fired almost exclusively with the onset of HVS (Fig. 9c). This latter cell was identified as a cortically projecting cell by antidromic stimulation and collision. The remaining 4 cells did not show reliable changes with behavior.

In 22 neurons, phasic modulation with HVS was observed. In 9 cells, the activity increased during the wave component of HVS (Fig. $9 b$, no star). In the remaining neurons the frequency increase preceded or coincided with the spike component of HVS (e.g., Fig. 9, $a, b$, open star). One of the rhythmic cells of 

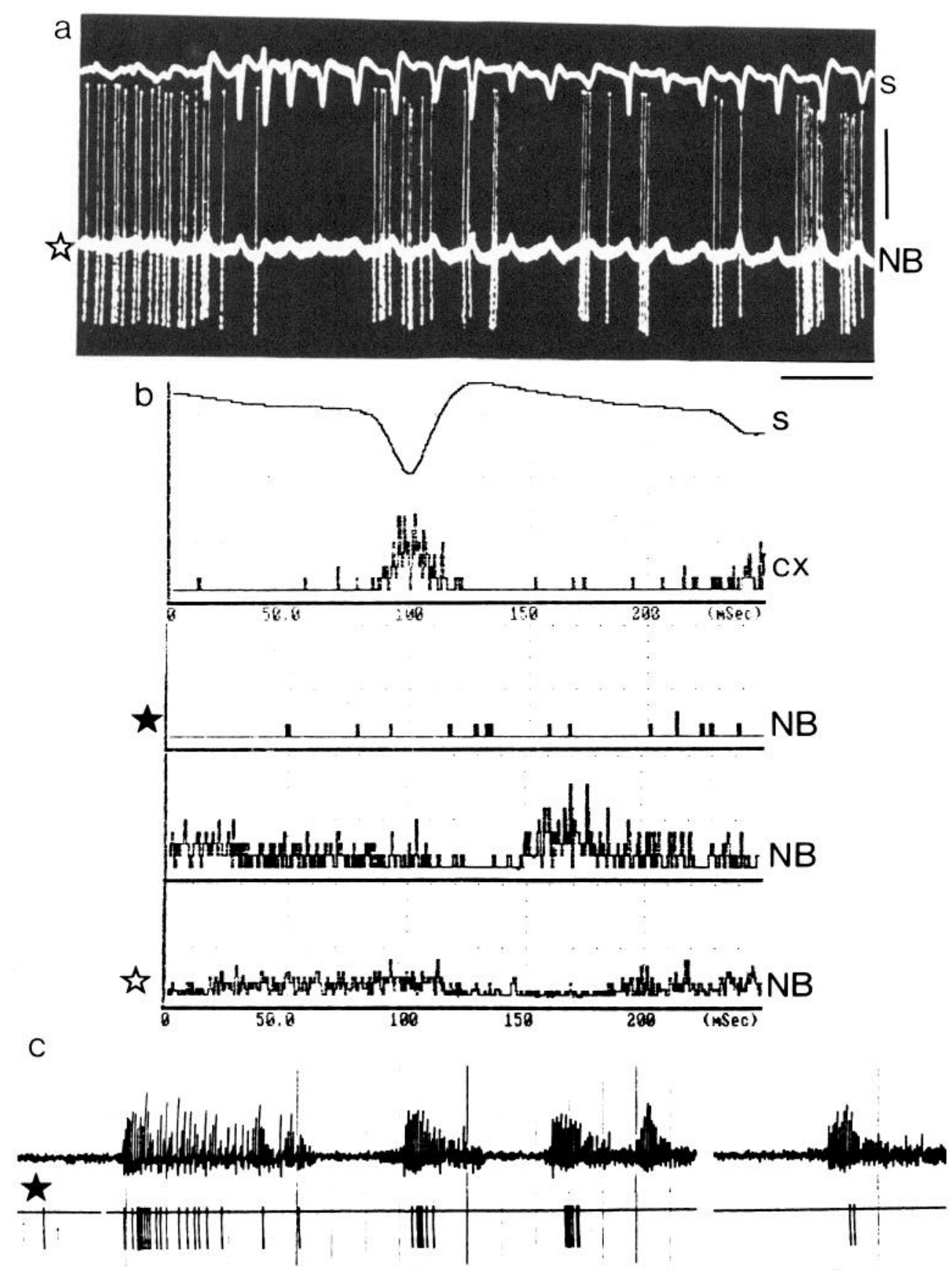

Figure 9. Cellular activity in NB in relation to HVS. $a$, Fast cell recorded from the substantia innominata. Note decreased frequency at the onset of HVS and phase-locked firing before the spike component of HVS. $b$, Perievent histograms $(n=50)$ of a cortical cell $(c x)$ and 3 types of NB cells recorded in the same rat, and averaged HVS recorded from the neocortical surface $(s) . c$, Polygraph recording of HVSs and discriminated unit discharges. Open and black stars in $b$, neurons shown in $a$ and $c$, respectively. Calibrations: $0.4 \mathrm{sec}(a) ; 2$ $\sec (c) ; 1 \mathrm{mV}(s$ in $a$ and $c) ; 0.5 \mathrm{mV}(N B$ in $a$ ).

the latter group was driven antidromically by neocortical stimulation.

Four neurons ( 3 in the substantia innominata and 1 in the internal capsule) displayed rhythmic activity at $5-7 / \mathrm{sec}$ during immobility without HVS.

\section{Effect of thalamic lesions on neocortical EEG}

Small to large doses (1.0-3.0 $\mu \mathrm{g} / 3 \mu \mathrm{l})$ of ibotenic acid were used to damage relatively circumscribed nuclei or extensive regions of the thalamus. The AChE pattern of the neocortex appeared 


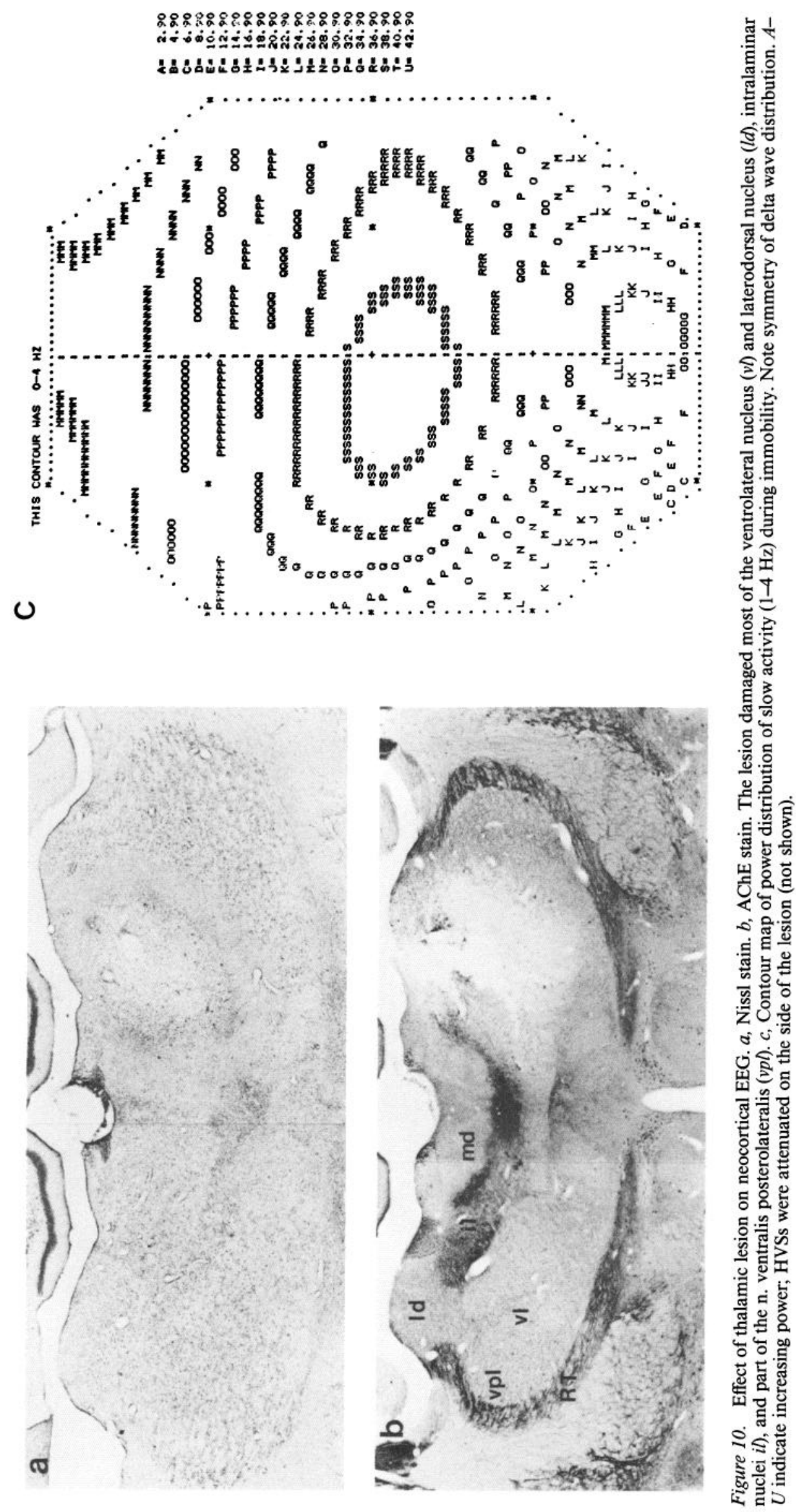



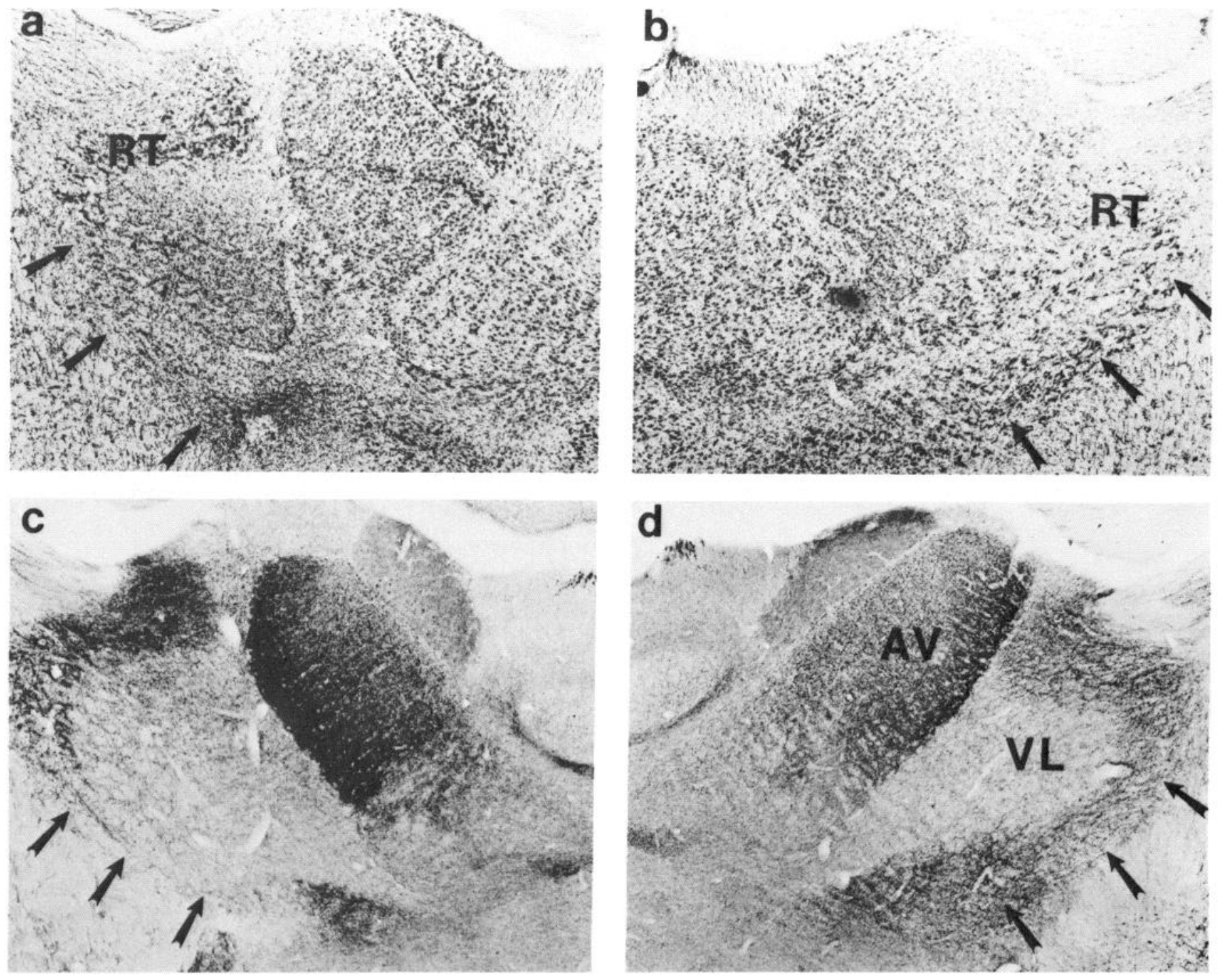

Figure 11. Ibotenic acid-induced lesion in n. reticularis thalami $(R T)$. The ventral borders of RT are marked by arrows. Note gliosis $(a)$ and absence of AChE-positive fibers $(c)$ on the lesioned side. $b, d$, Intact side. $V L, \mathrm{n}$. ventralis lateralis; $A V$, $\mathrm{n}$. ventralis anterior.

normal in all these rats. Independent of the extent and location of the thalamic lesions (Fig. 10), the neocortical EEG correlates with run-drink-immobility transitions remained essentially unchanged. The power spectra of EEG on the side of the lesion remained similar after lesion of the RT or following extensive lesions of the intralaminar nuclei and the ventrolateral nucleus.

HVSs occurring during immobility were severely affected, however. The spike component of HVS on the side of the lesion was suppressed in all rats, and no rhythmic cellular bursts were seen when HVS occurred in the contralateral (intact) hemisphere. The most effective locus for eliminating HVS was the RT (Figs. 11, 12). This suppressive effect was obvious immediately after recovery from anesthesia and persisted for several weeks, although some recovery of HVS was observed in all animals. Once spontaneous HVS was abolished, it could not be induced by either cortical stimulation or pentylenetetrazol (10$40 \mathrm{mg} / \mathrm{kg}$, i.p.). At larger doses, isolated spikes appeared in the EEG record; they were also ipsilateral to the lesion but were not rhythmic and asynchronous with the HVSs occurring in the intact hemisphere.
Despite the large asymmetry in HVS after thalamic lesions, the distribution of neocortical slow delta waves $(1-4 \mathrm{~Hz})$ remained symmetric in the absence of HVS (Fig. 12b).

\section{Effect of $N B$ lesions on neocortical EEG}

At the site of the lesion, there was a marked reduction in the number of CAT-positive cells (Fig. 13e). This was also reflected by the moderate-to-severe disappearance of AChE-labeled fibers in the vicinity of the injection site (Fig. 13c). The reduction of AChE staining in the neocortex on the side of the lesion was not severe. However, reduction in density of neocortical AChEpositive fibers was restricted to the cortical area, where EEG mapping showed an increased power of delta activity (see below).

Two-dimensional maps of the EEG power of the different frequency bands revealed that, following the lesion of NB, the greatest change occurred in the lower part $(1-4 \mathrm{~Hz})$ of the frequency spectrum. This resulted in an asymmetric map of power distribution, pinpointing the focus of the greatest change (Fig. 14). This asymmetry was present during all behaviors (Fig. 15), 


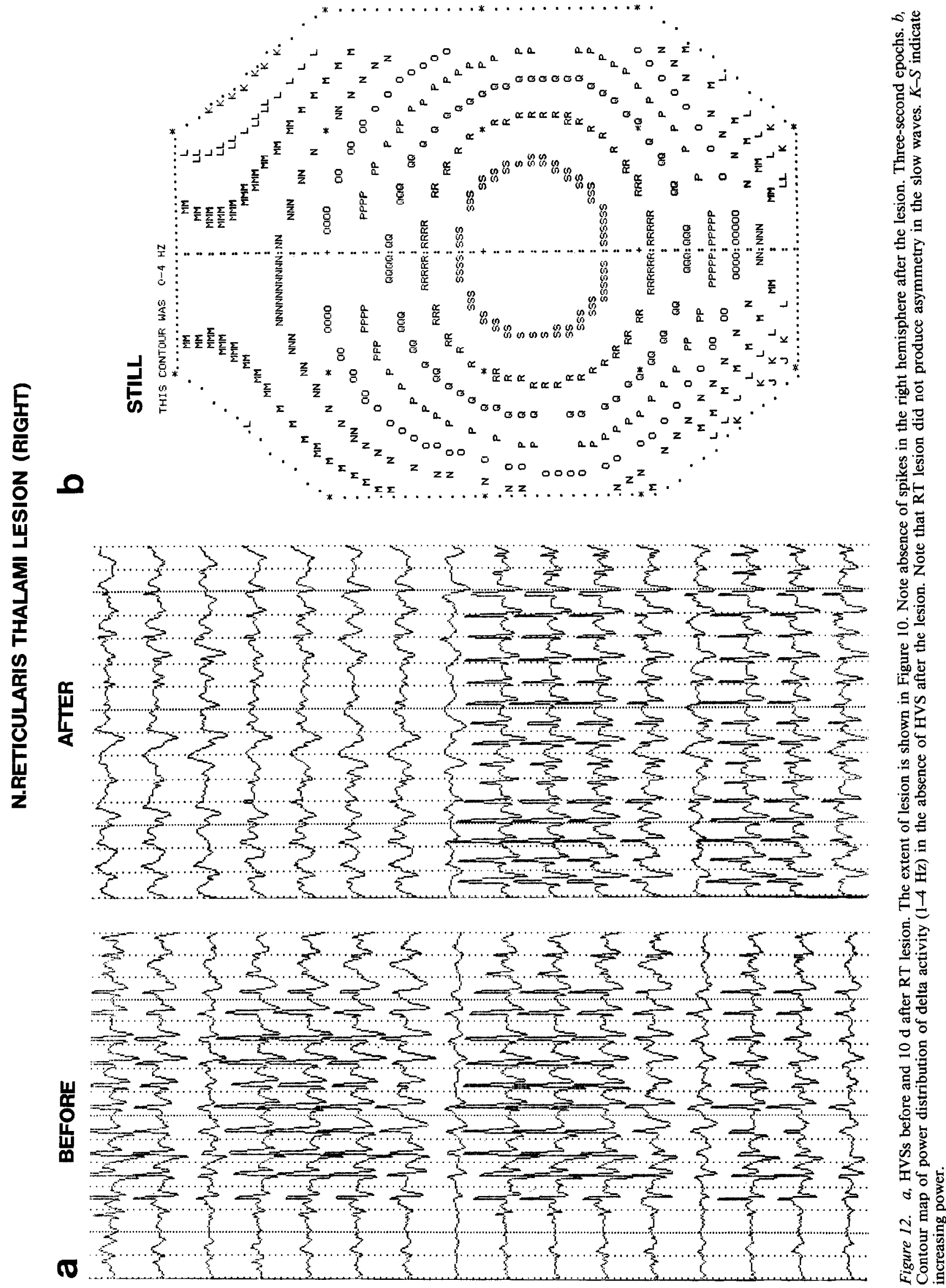



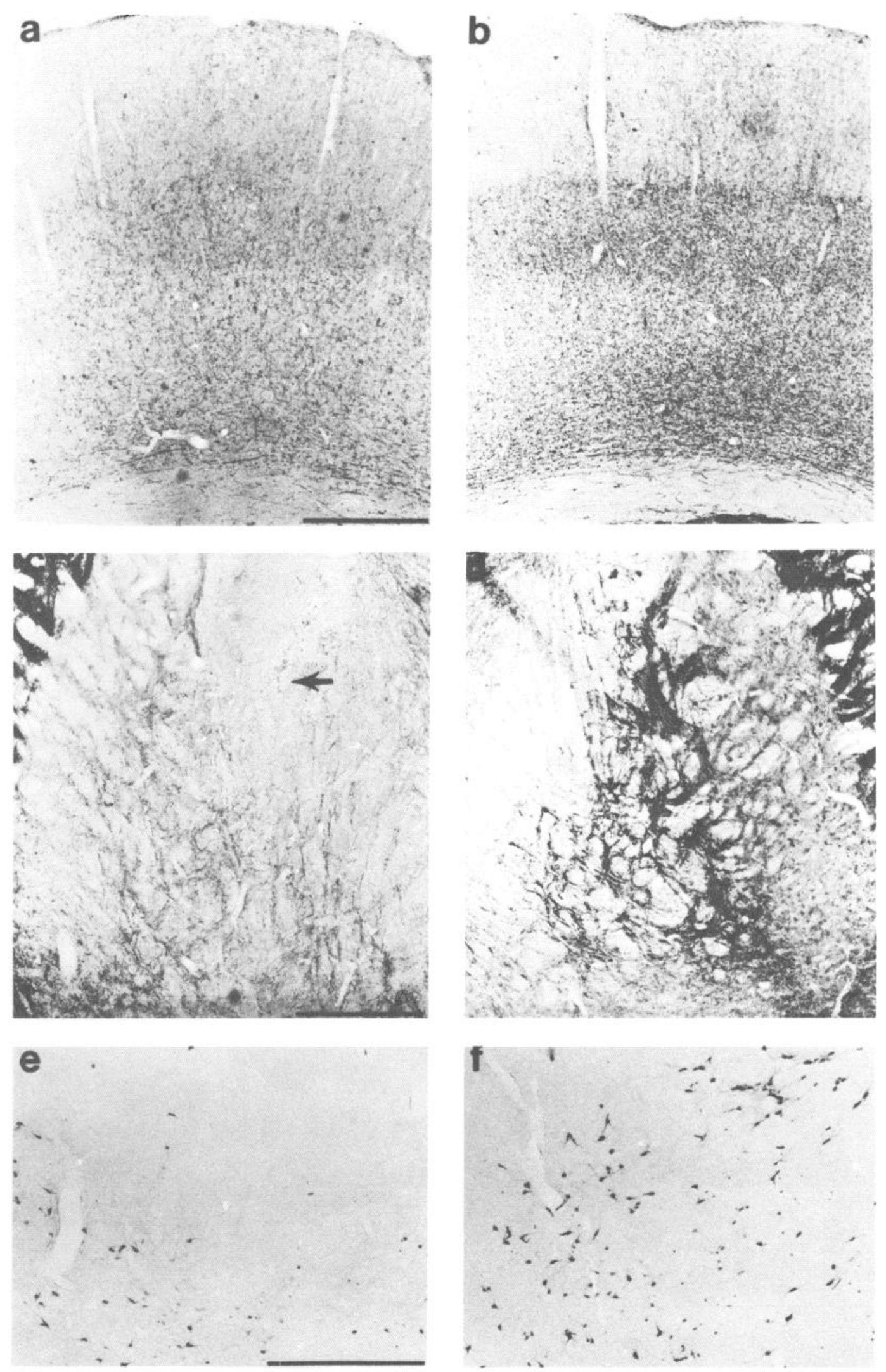

Figure 13. Ibotenic acid-induced lesion in the peripallidal region of NB. Left, Lesioned (right) side; right, intact sides. $a-d$, AChE-stained sections. Note decrease in the density of AChE-positive fibers in the injected NB and ipsilateral parietal cortex. Arrow in $c$ indicates cannula track. $e, f$, CATimmunostained sections. Note reduced number of CAT-positive cells in the damaged NB. Calibration, $0.5 \mathrm{~mm}$. 


\section{BEFORE LESION}

\section{NO DRUG}

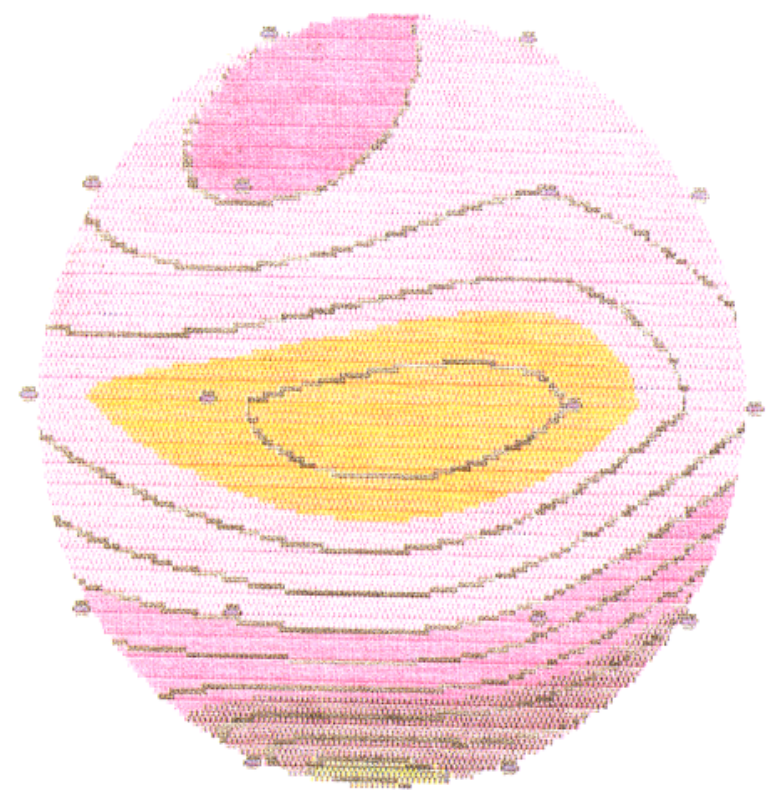

SCOPOLAMINE
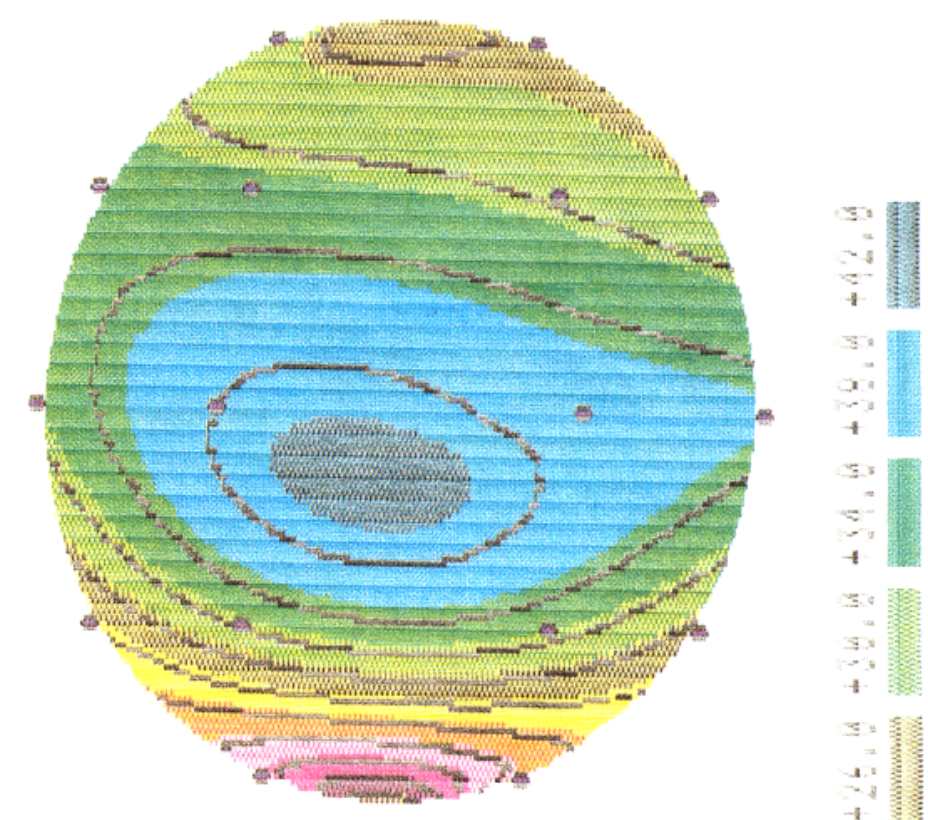

\section{AFTER R. NB LESION}
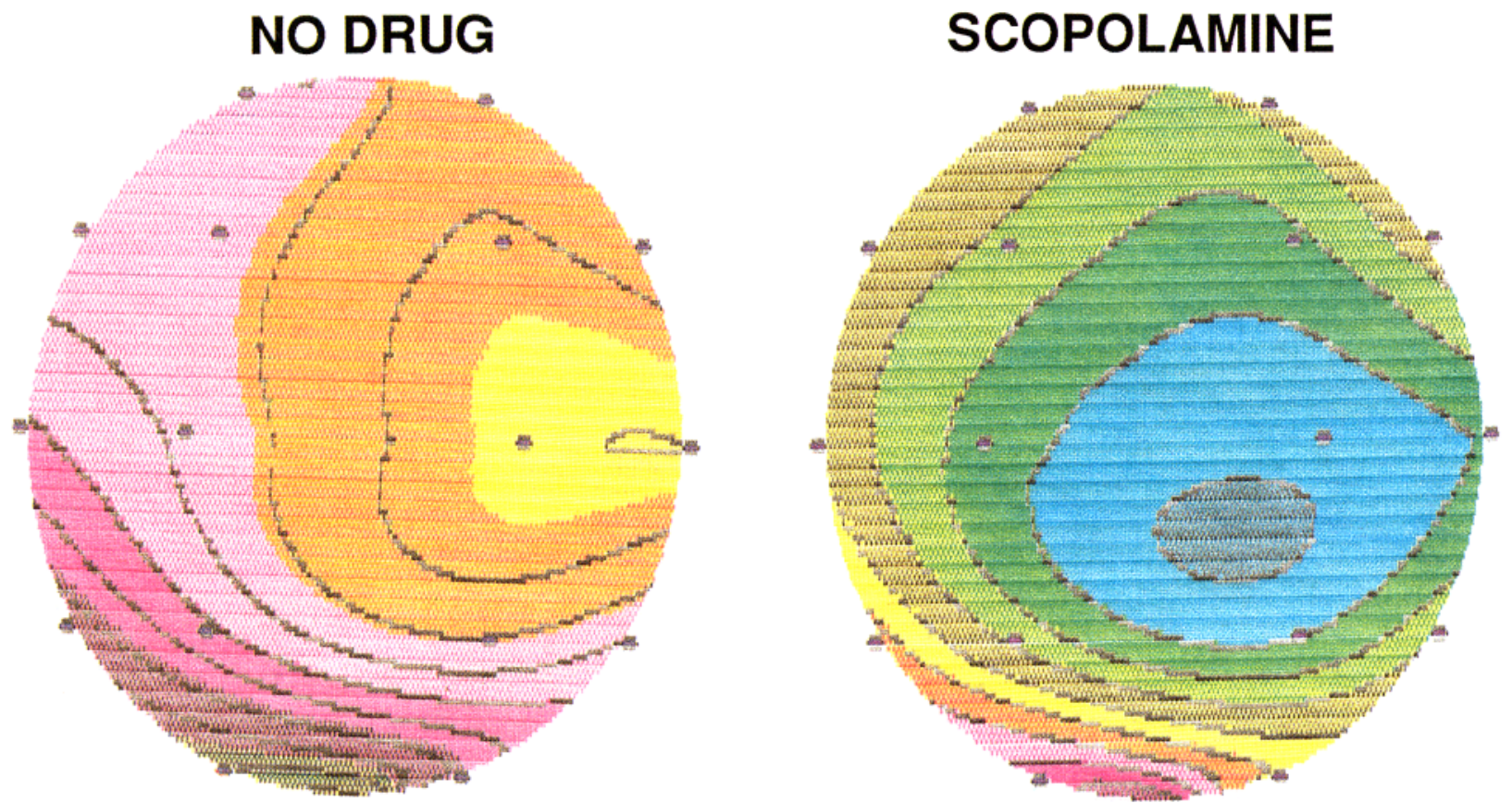

Figure 14. Contour maps of delta power $(1-4 \mathrm{~Hz})$ recorded during immobility. Note focal power increase on the side of NB lesion (lower left). Note also that scopolamine reduced the asymmetry between the damaged and intact hemispheres (lower right). Units of the color scale are arbitrary.

even though the absolute power values varied considerably across behaviors. The increase of power in the delta band was traced to 2 factors. First, when slow delta waves were present in the neocortical record, they were of larger amplitude in the lesioned hemisphere. Second, large-amplitude slow waves occurred ip- silateral to the NB damage at times when slow waves were absent from the contralateral (intact) side.

Administration of scopolamine $(0.2-5 \mathrm{mg} / \mathrm{kg})$ produced a substantial increase in the power of slow waves on both sides, and resulted in a decrease of the asymmetry ratio during drink- 


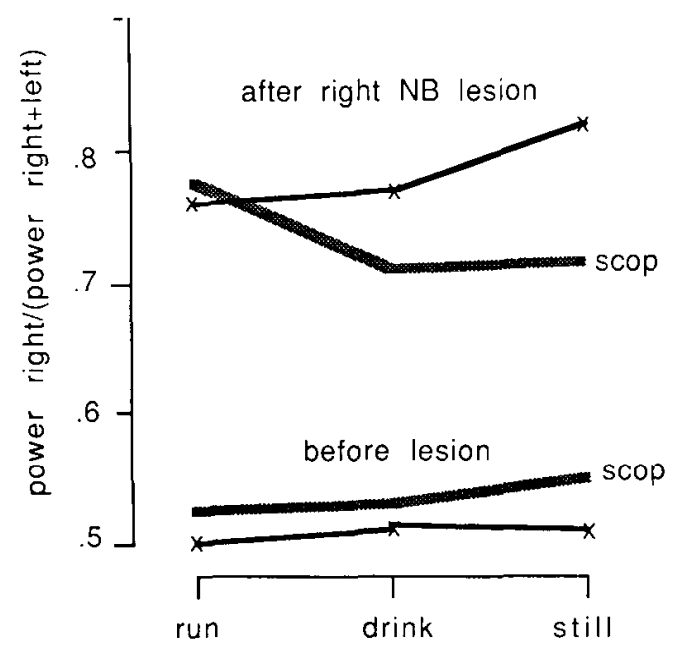

Figure 15. Asymmetry ratios of delta power $(1-4 \mathrm{~Hz})$ during different behaviors before and after NB lesion. Note that scopolamine (scop) reduced the interhemispheric differences during immobility (still).

ing and immobility. The decrease during immobility was statistically significant $(t=3.10, p<0.05)$ (Figs. 14, 15), indicating that scopolamine was more effective in producing slow waves on the intact side.

As for slow delta waves, the effect of NB lesion was similar to the effect of scopolamine administration. The power of slow waves increased after both scopolamine and damage to the NB. However, while the percentage increase of the power of highfrequency bands following scopolamine was more than the power increase of the slow waves, the increase of the power of higher frequencies $(8-20 \mathrm{~Hz})$ was less pronounced following the lesion of NB. In the 6 rats with bilateral lesions of the NB, the incidence of HVS was significantly $(p<0.02$; Mann-Whitney test) higher (median, 26/30 $\mathrm{min}$; range, $8-62 / 30 \mathrm{~min}$ ) than in their agematched controls (median, $3 / 30 \mathrm{~min}$; range, 1-8/30 min).

\section{Discussion}

The major findings of the present experiments are that the NB plays an essential role in neocortical activation, and that it exerts its effect by means of a dual mechanism. It activates the neocortex directly and, at the same time, it suppresses the rhythmgenerator mechanisms of the RT-thalamocortical system.

\section{$N B$ and the concept of ascending activation}

After the introduction of the generalized activation concept by Moruzzi and Magoun (1949), the question arose as to which anatomical/neurotransmitter systems were involved in the arousal mechanism. At the time, the most likely structural candidate was the reticular formation, with its assumed diffuse structure and widespread ascending projections. At the same time a good deal of pharmacological evidence suggested that ACh was involved in ncocortical activation (Wikler, 1952; Celesia and Jasper, 1966; Longo, 1966; Szerb, 1967; Jasper and Tessier, 1971; Vanderwolf and Robinson, 1981). The effects of ACh on neocortical electrical activity were supposed to be mediated by the axons of AChE-positive neurons of the reticular formation terminating in the neocortex (Shute and Lewis, 1967; Krnjevic et al., 1971; Phillis, 1980; Vanderwolf and Robinson, 1981) or in the thalamus (Jasper, 1949; Pape 2,1956 ; Steriade, 1970).
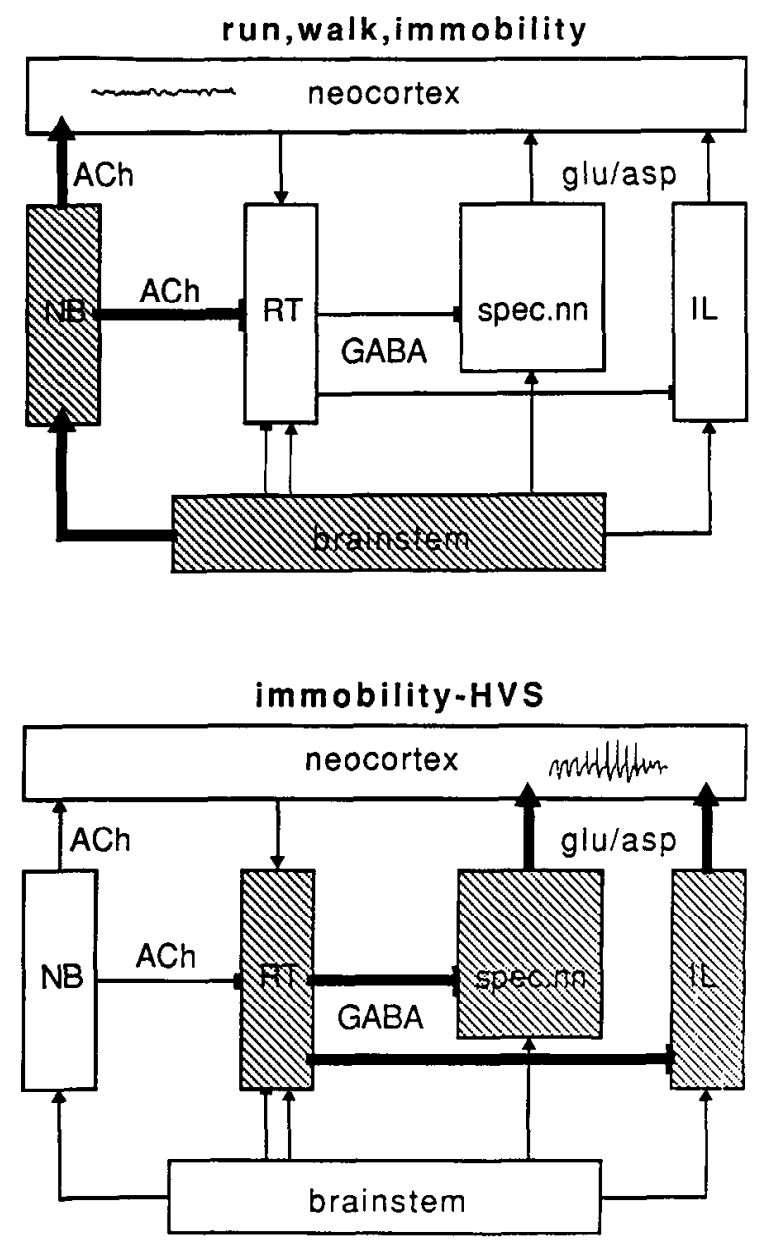

Figure 16. Schematic circuitries of the hypothesized mechanisms of neocortical activation (desynchronization) (top) and HVS (bottom). Pathways and structures playing a dominant role in the respective electrical patterns are indicated by heavy lines and shading. Arrows, excitatory paths; bars, inhibitory paths. During activation, NB exerts an excitatory effect on the neocortex and inhibits the RT-thalamocortical rhythmic generator circuitry. When the RT-thalamocortical system is released from the suppressive effect of the NB (bottom), rhythmic activity of RT cells phasically inhibits thalamocortical cells and induces rhythmic rebound burst firing in these cells, resulting in rhythmic depolarization of cortical cells. $N B$, nucleus basalis; $R T$, n. reticularis thalami; spec.nn, "specific" nuclei of thalamus; $I L$, intralaminar thalamic nuclei; $H V S$, high-voltage spindle.

Abundant information has emerged over the past years that weakens the exclusive role of the above-outlined anatomical circuitry of neocortical activation. Direct cholinergic reticulocortical connections are nonexistent (Fibiger, 1982; Mesulam et al., 1983). The only reticular-thalamic-cortical path with the required diffuse projection has remained the intralaminar nuclei, which have widespread terminations in the neocortex (Walker, 1938; Jones, 1985) and are innervated by cholinergic ccll groups located in the midbrain (Hallanger et al., 1987). However, Fox and Armstrong-James (1986) have recently suggested that the intralaminar nuclei are responsible for the induction of neocortical slow waves and not desynchronization. In our studies, circumscribed or large lesions of the thalamus, involving RT and the intralaminar nuclei, failed to alter behavior-dependent EEG changes in the neocortex. The role of RT in HVS will be discussed below. Taken together, these findings indicate that thalamocortical fibers, either specific or non- 
specific, do not play as vital a role in neocortical arousal as has traditionally been believed (see also Stewart et al., 1984). The cholinergic input to the thalamus, however, may play an important function in facilitating the effectiveness of other inputs to the thalamus (Steriade, 1970; Marshall and McLennan, 1972).

On the other hand, our data provide evidence that activation of the neocortex is dependent on the integrity of the NB. Circumscribed and restricted lesions of the cortically projecting basal forebrain group (see Ch. 4 of Mesulam et al., 1983) resulted in slow delta waves at their cortical target areas during all behaviors, although the power in the delta band was significantly greater during immobility and drinking than during running. In this respect, the effect of NB lesion was similar to that of scopolamine.

The circumscribed EEG changes, as observed in our mapping studies, are in agreement with anatomical findings indicating that the NB projection to the cortex is topographically specific (Price and Stern, 1983; Bigl et al., 1984; Saper, 1984).

Scopolamine produced less effect on the side of the NB lesion, as indicated by the decrease of the asymmetry index after scopolamine treatment. This may be explained by the reduced number of cholinergic terminals, with proportionally less ACh release in the damaged hemisphere. The partial effectiveness of cholinergic blockade on the side of NB damage can be explained by the incomplete nature of the lesion or by the blockade of the activity of the cholinergic neurons intrinsic to the neocortex. The above findings suggest that the arousing effect of the NB is mediated mainly by a cholinergic-muscarinic mechanism.

Recordings of single-unit activity in the NB lend further support to the hypothesis that basal forebrain neurons may activate neocortical cellular activity. The majority of our NB cells doubled their discharge rates during movement, as compared to during an immobile state. A comparable increase of firing frequency was recently reported for neurons recorded from the magnocellular preoptic area in cats during the sleep-wake transition (Detari et al., 1984; Szymusiak and McGinty, 1986). Furthermore, in urethane-anesthetized rats, most neurons in the preoptic area responded with severalfold increases to odor stimuli, with concurrent EEG desynchronization (Pfaff and Gregory, 1971). In diazepam-sedated restrained rats, three-fourths of the responsive units in NB showed robust excitatory reactions to acoustic conditioned stimuli (Rigdon and Pirch, 1986). The inverse relationship between the firing rates of NB neurons (lowest during immobility) and the power of the EEG slow waves (highest during immobility), as observed here, adds additional support to the suggestion that active neurons in the NB keep the neocortical EEG in a desynchronized state.

The behavioral and EEG-related discharge profiles of NB neurons, together with the electrophysiological evidence that $\mathrm{ACh}$ acts as a slow excitatory neurotransmitter in the neocortex (Krnjevic et al., 1971; Swartz and Woody, 1979; Phillis, 1980; Cole and Nicoll, 1984), support the hypothesis that increased neuronal firing of the NB provides a steady background of neocortical activity that may enhance the effects of other afferents to the neocortex (Sillito and Kemp, 1983). We propose that the NB-neocortical projection may be conceived as having a role compatible with the broad functional concept of the activation theory, i.e., parallel ascending influences that enable the neocortical mantle to carry out its specific functions through the activating process that we call "arousal." This suggestion does not exclude the reticular formation as playing an important role in thalamic and neocortical activation, but focuses attention on the NB as an essential relay for the arousing effects.

Decreased activity of NB cells (immobility-drowsy state) or interference with the NB-cortical system (scopolamine, NB lesion) resulted in slow delta waves. The observed potential minimum of delta waves at the upper border of layer $\mathrm{V}$ and an abrupt phase-reversal at the same depth are compatible with a single, dipole-like behavior (Peronnet et al., 1981; Rappelsberger et al., 1981). Concurrent with delta waves, neurons in the cortex fired in a synchronized burst-pause pattern. The suppression of cellular firing both at the multi-unit and single-unit level coincided with the positive portion of delta waves in layers $\mathrm{V}$ and VI. In traditional terms, such a unit-wave relationship could be best described by assuming that inhibitory synapses, terminating on the cell bodies of layer $V$ pyramidal neurons, set up the extracellular local positivity (active source) (Calvet et al., 1973; Ball et al., 1977). An important link in the latter hypothesis is missing, however. We could not find neurons in any cortical layers that increased their discharge rates specifically during the positive portion of layer $V$ delta waves. Instead, we found that putative local circuit neurons also decreased their activity during local positivity in deep layers.

On the basis of these findings, we suggest that extracellular delta waves are not necessarily a result of synaptic activity, but may reflect summation of long-lasting afterhyperpolarizations of layer V pyramidal neurons. Such long-lasting afterpotentials (200-500 msec) are typical in cortical pyramidal cells (Hablitz, 1981; Wong and Prince, 1981; Connors et al., 1982). These afterhyperpolarizations are due in part to a $\mathrm{Ca}^{2+}$-mediated $\mathrm{K}^{+}$ conductance change, which is attenuated considerably by local application of ACh (Krnjevic et al., 1971; Benardo and Prince, 1982; Cole and Nicoll, 1984; McCormick and Princc, 1986). We hypothesize that the suppression of slow delta waves and the resulting low-voltage EEG during neocortical arousal are due mainly to the blockade of the long-lasting hyperpolarizations in pyramidal cells as a result of the activation of the cholinergic NB afferents to the neocortex.

\section{Cellular generation of $H V S$}

HVS occurred with highest amplitude over the sensorimotor area, while the rat was sitting motionless. Several seconds of immobility must elapse before the emergence of a HVS, indicating that the motionless state is not a cause, but a necessary condition, of HVS. Since the first description of this peculiar EEG rhythm (Gottesmann, 1967; Klingberg and Pickenhain, 1968) several investigators have reported the occurrence of HVS in a portion or all of thcir animals, and have associated it with various physiological and pathological processes (for reviews, see Ryan, 1984; Kaplan, 1985).

Several observations of the present experiments suggest that the rhythm generator of neocortical HVS must be sought in the RT or at the level of the NB-RT circuitry. First, in the absence of the neocortex, the thalamic pattern of HVS remained identical to the normal rhythmic cellular discharges. Second, lesion of the RT strongly attenuated or completely abolished HVS in the ipsilateral hemisphere. Third, neurons in the RT and NB displayed rhythmic cellular patterns in the absence of HVS. Fourth, the anteromedial nucleus, which does not receive afferents from RT (Steriade et al., 1984), did not display rhythmicity (see also Mulle et al., 1985). The above findings confirm and extend the previous suggestion, based on an elegant series of experiments in the cat (Steriade et al., 1985, 1987b), that the 
"pacemaker" of rhythmic phenomena in the neocortex may reside in $R T$.

In addition to its rhythmicity, activity of the thalamocortical cells was qualitatively different during HVS. While, during movement and immobility, neurons showed sustained singlespike discharges of varying frequency, during HVS they displayed mainly rhythmical burst discharges of 1-7 spikes. Recent observations in the cat (Steriade et al., 1985) and in guinea pig thalamic slice preparation (Llinás and Jahnsen, 1982; Jahnsen and Llinás, 1984) suggest that the tonic and phasic discharges of thalamocortical cells are brought about by diametrically opposite mechanisms. Depolarization activates a $\mathrm{Na}^{+}$conductance and consequent tonic firing. Phasic discharges, on the other hand, are generated by a low-threshold, tetrodotoxin-resistant, slow $\mathrm{Ca}^{2+}$ spike. This potential is inactivated near or above firing threshold, but can be deinactivated by a moderate hyperpolarization of the cell membrane.

The out-of-phase discharges of RT and thalamocortical neurons in relation to HVS, as observed here in freely moving rats, are of physiological relevance to the above intracellular observations. Rhythmic discharges of the GABAergic RT cells (Houser et al., 1980; Oertel et al., 1983) are assumed to phasically hyperpolarize thalamocortical neurons and, in the absence of other cxcitatory influences, voltage- and time-dependent rebound spikes occur in a rhythmic manner (Jahnsen and Llinás, 1984).

All evidence indicates that terminals of thalamocortical axons make excitatory synapses with neocortical pyramidal and other types of cells, including inhibitory interneurons (Jones, 1975, 1985; Colonnier, 1981; Ottersen et al., 1983). Synchronous discharge of large populations of neurons in the specific relay and nonspecific intralaminar nuclei may rhythmically depolarize and discharge neurons in the cortex. The complexity of intracortical connections and the multiple termination of various thalamic afferents in different cortical layers (Herkenham, 1980) make it difficult to relate the extracellular current flow during HVS to synaptic events. The gradual phase-shift of HVS with depth is compatible with a model of multiple, but slightly phase-delayed, dipoles along the somatodendritic surface of vertically oriented neuronal elements in the neocortex. A similar phase-shifted multiple-dipole model was recently described in the hippocampus (Buzsáki et al., 1986). By producing circumscribed lesions in different thalamic nuclei, depth profile measurements in the neocortex may reveal the single-dipole elements of the HVS.

It has been previously observed that rhythmic oscillations in the thalamus can be triggered by cortical (Steriade and Wyzinski, 1972) or thalamic (Purpura, 1969; Chocolova et al., 1977) stimulation. The present study revealed that there are other conditions prerequisite to the effectiveness of stimulus volleys. We found that stimulation was capable of triggering HVS only during relaxed immobility, when spontaneous HVS could also occur. It was during the same behavioral condition that rhythmic discharges in individual RT and NB units were also seen, coinciding with a decrease of firing rates in neocortical and thalamocortical units. We hypothesize that the low level of activity in the thalamic and cortical cells during immobility is a necessary, but not sufficient, condition for the occurrence of widespread synchronous and rhythmic activity. When individual rhythmic cells in RT become phase-locked, e.g., induced by a synchronous volley, the population output from the RT may impose its rhythmicity onto the thalamocortical circuitry.

Rhythmic discharges and focal waves in the thalamus remain after neocortical ablation (Morison and Basset, 1945; Villablanca, 1974; the present study). Furthermore, after surgical disconnection of RT from all other thalamic nuclei, rhythmicity survives in RT (Steriade et al., 1987a). Although neocortical and thalamic feedback afferents may also play an important role in triggering HVS (Gloor et al., 1979), the above-discussed findings suggest that the essential control circuitry involves extrathalamic subcortical mechanisms.

\section{Nucleus basalis control of thalamic activity}

It has been suggested previously that cholinergic afferents exert an inhibitory effect on RT cells, but these studies attributed the effects of ACh to the ascending brain stem reticular system (BenAri et al., 1976; McCormick and Prince, 1986; Steriade et al., 1987b). It has recently been discovered in the cat (Steriade et al., 1987b) and rat (Hallanger et al., 1987; Levey et al., 1987) that the major subcortical input to the RT derives from the cholinergic and non-cholinergic neurons of the NB. Following injection of a retrograde tracer into the RT, over one-third of the cholinergic and a large population of the non-cholinergic cells in NB were labeled. The present findings, together with these anatomical observations, suggest that the cholinergic NB may effectively gate thalamic rhythmicity through the RT.

At the onset of HVS, most neurons in the NB decreased their discharge rates. Over half of the NB cells showed a clear-cut relationship with HVS in the present study. Although only 2 of them could be driven antidromically from the neocortex, the high incidence of rhythmic units in the NB suggests that at least a portion of them were cholinergic projection cells (Aston-Jones et al., 1984; Reiner et al., 1987). The rhythmic activity of NB neurons could be produced by either cortical or thalamic efferents to the NB (Russchen et al., 1985).

The majority of the NB cells increased their discharge rates during walking and body movements. The increased discharges of NB cells during movement may effectively suppress rhythmic bursting and population synchrony of RT neurons. This suggestion is supported by the significantly higher incidence of HVS in animals with bilateral lesion of the NB and following a small dose of scopolamine. The release from cholinergic suppression may also explain the high incidence of HVS in aged rats (Buzsàki et al., 1988) with shrunken cholinergic cells in the NB (Armstrong et al., 1987).

\section{Conclusions}

A schematic circuitry of our findings and hypotheses regarding the activation of the neocortex is shown in Figure 16. We suggest that the cholinergic NB plays an important role in activation of the cerebral cortex, and it may exert its effects via a dual mechanism. First, the cortical cholinergic projection from NB directly influences neocortical cells and makes them more responsive to other afferent influences. Second, the cholinergic input from NB to RT suppresses the rhythmic oscillations of the "pacemaker" neurons of this thalamic nucleus. Thus, increased activity of NB neurons, as observed, e.g., during walking behavior, will insure neocortical activation by direct release of $\mathrm{ACh}$ in the neocortex and by dampening the oscillatory influences of the thalamus. The model predicts that decreased activity in NB (e.g., immobility or lesion) will result in the increased power of slow delta waves. When the RT is released from the inhibitory effects of NB (immobility, aging), the synchronized rhythmic discharges of the GABAergic RT neurons phasically inhibit the thalamocortical neurons. Hyperpolarization and phasic release 
from inhibition will result in rhythmic rebound bursting of thalamocortical cells and consequent rhythmic depolarization and firing of neocortical neurons.

\section{References}

Armstrong, D. M., C. B. Saper, and A. I. Levey (1983) Distribution of cholinergic neurons in rat brain: Demonstrated by the immunohistochemical localization of choline acetyltransferase. J. Comp. Neurol. 216: 53-68.

Armstrong, D. M., G. Bruce, L. B. Hersh, and R. D. Terry (1986) Choline acetyltransferase immunoreactivity in neuritic plaques of Alzheimer brain. Neurosci. Lett. 71: 229-234.

Armstrong, D. M., G. Buzsáki, K. S. Chen, R. Ruiz, R. Sheffield, and F. H. Gage (1987) Cholinergic neurotransmission in the aged rat: A behavioral, physiological, and anatomical study. Soc. Neurosci. Abstr. 13: 434.

Aston-Jones, G., R. Shaver, and T. G. Dinan (1984) Cortically projecting nucleus basalis neurons in rat are physiologically heterogeneous. Neurosci. Lett. 46: 19-24.

Ball, G. J., P. Gloor, and N. Schaul (1977) The cortical electromicrophysiology of cats. Electroencephalogr. Clin. Neurophysiol. 43: 346363.

Bartus, R. T., R. L. Dean, B. Beer, and A. S. Lippa (1982) The cholinergic hypothesis of geriatric memory disfunction. Science 217:408417 .

Benardo, L. S., and D. A. Prince (1982) Cholinergic excitation of mammalian hippocampal pyramidal cells. Brain Res. 249: 315-331.

Ben-Ari, Y., R. Dingledine, I. Kanazawa, and J. S. Kelly (1976) Inhibitory effects of acetylcholine on neurones in the feline nucleus reticularis thalami. J. Physiol. (Lond.) 261: 647-671.

Bickford, R. G. (1981) A combined EEG and evoked potential procedure in clinical EEG (automated cerebral electrogram-ACE test). In Recent Advances in EEG and EMG Data Processing, N. Yamaguchi and K. Fujisaura, eds., pp. 217-235, Elsevier, Amsterdam.

Bickford, R. G., and B. Allen (1986) A simple add-on personal computer procedure for color displays of electrophysiological data: Advantage and pitfalls. In Topographic Mapping of Brain Electrical Activity, F. H. Duffy, ed., pp. 203-216, Butterworths, Boston.

Bigl, V., N. J. Woolf, and L. L. Butcher (1984) Cholinergic projections from the basal forebrain to frontal, parietal, temporal, occipital, and cingulate cortices: A combined fluorescent tracer and acetylcholinesterase analysis. Brain Res. Bull. 8: 727-749.

Buzsáki, G. (1986) Hippocampal sharp waves: Their origin and significance. Brain Res. 398: 242-252.

Buzsàki, G., L. S. Leung, and C. H. Vanderwolf (1983) Cellular basis of hippocampal EEG in the behaving rat. Brain Res. Rev. 6: 139171 .

Buzsáki, G., J. Czopf, I. Kondảkor, and L. Kellènyi (1986) Laminar distribution of hippocampal slow activity (RSA) in the behaving rat Current source density analysis, effects of urethane and atropine. Brain Res. 365: 125-137.

Buzsáki, G., R. G. Bickford, D. M. Armstrong, G. Ponomareff, K. Chen, R. Ruiz, L. J. Thal, and F. H. Gage (1988) EEG activity in the neocortex of freely moving young and aged rats. Neuroscience (in press).

Calvet, J., M. Fourment, and T. Michel (1973) Electrical activity in neocortical projection and association areas during slow wave sleep. Brain Res. 52: 173-187.

Celesia, G. G., and H. H. Jasper (1966) Acetylcholine released from cerebral cortex in relation to state of activation. Neurology 16:10531064.

Chocolova, L., M. Kolinova, and J. Fischer (1977) Stimulation of the thalamus and its effect on electrographic manifestation of the brain in unrestrained rats. Physiol. Bohemoslov. 26: 507-515.

Cole, A. E., and R. A. Nicoll (1984) Characterization of a slow cholinergic postsynaptic potential recorded in vitro from rat hippocampal pyramidal cells. J. Physiol. (Lond.) 352: 173-188.

Colonnier, M. (1981) The electron-microscopic analysis of the neuronal organization of the cerebral cortex. In The Organization of the Cerebral Cortex, F. O. Schmitt, F. G. Worden, G. Adelman, and S. G. Dennis, eds., pp. 125-152, MIT Press, Cambridge, London.

Connors, B. W., M. J. Gutnick, and D. A. Prince (1982) Electrophysiological properties of neocortical neurons in vitro. J. Neurophysiol. 48: 1302-1320.
Détári, L., G. Juhász, and T. Kukorelli (1984) Firing properties of cat basal forebrain neurons during sleep-wakefulness cycles. Electroencephalogr. Clin. Neurophysiol. 58: 362-368.

Divac, I. (1975) Magnocellular nuclei of the basal forebrain project to neocortex, brain stem, and olfactory bulb. Review of some functional correlates. Brain Res. 93: 385-398.

Fibiger, H. C. (1982) The organization and some projections of cholinergic neurons of the mammalian forebrain. Brain Res. Rev. 4: 327388.

Fox, K., and M. Armstrong-James (1986) The role of the anterior intralaminar nuclei and $N$-methyl $\mathrm{D}$-aspartate receptors in the generation of spontaneous bursts in rat cortical neurones. Exp. Brain Res. 63: 505-518.

Gloor, P., A. Pellegrini, and G. K. Kostopoulos (1979) Effects of changes in cortical excitability upon the epileptic bursts in generalized penicillin epilepsy of the cat. Electroencephalogr. Clin. Neurophysiol. 46: $274-289$.

Gottesmann, C. (1967) Recherche sur psychophysiologie du sommeil chez la rat. Thesis, Doctor of Natural Science, Presse du Palais Royal, pp. 1-156.

Hablitz, J. J. (1981) Effects of intracellular injections of chloride and EGTA on postepileptiform-burst hyperpolarizations in hippocampal neurons. Neurosci. Lett. 22: 159-163.

Hallanger, A. E., A. I. Levey, H. J. Lee, D. B. Rye, and B. H. Wainer (1987) The origins of cholinergic and other subcortical afferents to the thalamus in the rat. J. Comp. Neurol. 262: 105-124.

Herkenham, M. (1979) The afferent and efferent connections of the ventromedial thalamic nucleus of the rat. J. Comp. Neurol. 183: 487518.

Herkenham, M. (1980) Laminar organization of thalamic projections to the rat neocortex. Science 207: 532-535.

Herz, A. (1959) Uber die Wirkung von Scopolamin und ahulichen Substanzen auf bedingte Reaktionen. Arch. Exp. Pathol. Pharmakol. 236: $110-112$.

Houser, C. R., J. E. Vaughn, R. P. Barber, and E. Roberts (1980) GABA neurons are the major cell type of the nucleus reticularis thalami. Brain Res. 200: 341-354.

Houser, C. R., G. D. Crawford, P. M. Salvaterra, and J. E Vaughn (1985) Immunocytochemical localization of choline acetyltransferase in rat cerebral cortex: A study of cholinergic neurons and synapses. J. Comp. Neurol. 234: 17-34.

Jahnsen, H., and R. Llinás (1984) Electrophysiological properties of guinea-pig thalamic neurones: An in vitro study. J. Physiol. (Lond.) 349: 205-226.

Jasper, H. H. (1949) Diffuse projection systems: The integrative action of the thalamic reticular system. Electroencephalogr. Clin. Neurophysiol. 1: 405-420.

Jasper, H. H., and J. Tessier (1971) Acetylcholine liberation from cerebral cortex during paradoxical (REM) sleep. Science 172: 601602.

Jones, E. G. (1975) Some aspects of the organization of the thalamic reticular complex. J. Comp. Neurol. 162: 285-308.

Jones, E. G. (1985) The Thalamus, Plenum, New York.

Jones, E. G., H. Burton, C. B. Saper, and L. W. Swanson (1976) Midbrain diencephalic and cortical relationships of the basal nucleus of Meynert and associated structures in primates. J. Comp. Neurol. 167. 385-420.

Kaplan, B. J. (1985) The epileptic nature of rodent electrocortical polyspiking is still unproven. Exp. Neurol. 88: 425-436.

Klingberg, F., and L. Pickenhain (1968) Das Aufreten von "Spindelenthadinigen" bei der Ratte in Beziehung zum Verhalten. Acta Biol. Med. Ger. 20: 45-54.

Koelle, G. B. (1956) The histochemical localization of cholinesterase in the central nervous system of the rat. J. Comp. Neurol. 100:211235.

Krnjevic, K., R. Pumain, and L. Renaud (1971) The mechanism of excitation by acetylcholine in the cerebral cortex. J. Physiol. (Lond.) 215: 247-268.

Lehmann, J., J. I. Nagy, S. Atmadja, and H. C. Fibiger (1980) The nucleus basalis magnocellularis: The origin of a cholinergic projection to the neocortex of the rat. Neuroscience 5: 1161-1174.

Levey, A. I., A. E. Hallanger, and B. H. Wainer (1987) Cholinergic nucleus basalis neurons may influence the cortex via the thalamus. Neurosci. Lett. 74: 7-13.

Lindvall, O., A. Björklund, A. Nobin, and U. Stenevi (1974) The 
adrenergic innervation of the rat thalamus as revealed by the glyoxylic acid fluorescence method. J. Comp. Neurol. 154: 314-348.

Lipski, J. (1981) Antidromic activation of neurones as an analytical tool in the study of the central nervous system. J. Neurosci. Methods 4: $1-32$.

Llinás, R., and H. Jahnsen (1982) Electrophysiology of mammalian thalamic neurones in vitro. Nature 297: 406-408.

Lo Conte, G., F. Casamenti, V. Bigl, E. Milaneschi, and G. Pepeu (1982) Effect of magnocellular forebrain nuclei lesions on acetylcholine output from the cerebral cortex, electrocorticogram and behavior. Arch. Ital. Biol. 120: 176-188.

Longo, V. G. (1966) Effects of scopolamine and atropine on electroencephalographic and behavioral reactions due to hypothalamic stimulation. J. Pharmacol. 116: 198-208.

Lynch, J. C. (1980) The functional organization of posterior parietal association cortex. Behav. Brain Sci. 3: 385-534.

Marshall, K. C., and H. McLennan (1972) The synaptic activation of neurones of the feline ventrolateral thalamic nucleus: Possible cholinergic mechanisms. Exp. Brain Res. 15: 472-483.

McCormick, D. A., and D. A. Prince (1986) Acetylcholine induces burst firing in thalamic reticular neurons by activating potassium conductance. Nature 319: 402-405.

McGeer, P. L., E. G. McGeer, and T. Nagai (1983) GABAergic and cholinergic indices in various regions of rat brain after intracerebral injections of folic acid. Brain Res. 260: 107-116.

McGinty, D. J., and M. B. Sterman (1968) Sleep suppression after basal forebrain lesions in cat. Science 160: 1253-1255.

Mesulam, M.-M., and G. W. Van Hoesen (1976) Acetylcholinesteraserich projections from the basal forebrain of the rhesus monkey to neocortex. Brain Res. 109: 152-157.

Mesulam, M.-M., E. J. Mufson, B. H. Wainer, and A. I. Levey (1983) Central cholinergic pathways in the rat: An overview based on an alternative nomenclature (Ch1-Ch6). Neuroscience 4: 1185-1201.

Moore, R. Y., A. E. Halaris, and B. E. Jones (1978) Serotonin neurons of the midbrain raphe: Ascending projections. J. Comp. Neurol. 180: 417-438.

Morison, R. S., and D. L. Basset (1945) Electrical activity of the thalamus and basal ganglia in decorticate cats. J. Neurophysiol. 8: 309-414.

Moruzzi, G., and H. W. Magoun (1949) Brainstem reticular formation and activation of the EEG. Electroencephalogr. Clin. Neurophysiol. 1: $455-473$.

Mulle, C., M. Steriade, and M. Deschênes (1985) Absence of spindle oscillations in the cat anterior thalamic nuclei. Brain Res. 334: 169171.

Oertel, W. H., A. M. Graybiel, E. Mugnaini, R. P. Elde, D. E. Schmechel, and I. J. Kopin (1983) Coexistence of glutamic acid decarboxylase and somatostatin-like immunoreactivity in neurons of the feline nucleus reticularis thalami. J. Neurosci. 3: 1322-1332.

Ottersen, O. P., B. O. Fisher, and J. Storm-Mathisen (1983) Retrograde transport of $\mathrm{D}\left({ }^{3} \mathrm{H}\right)$ aspartate in thalamocortical neurons. Neurosci. Lett. 42: 19-24

Papez, J. W. (1956) Central reticular path to intralaminar and reticular neurons of the thalamus for activating EEG related to consciousness. Electroencephalogr. Clin. Neurophysiol. 8: 117-128.

Peronnet, I., M. Sindou, A. Laviron, F. Quoex, and P. Gerin (1981) Human cortical electrogenesis: Stratigraphy and spectral analysis. In Synchronization of EEG Activity in Epilepsies, H. Petsche and M. A. B. Brazier, eds., pp. 235-261, Springer, Heidelberg.

Pfaff, D. W., and E. Gregory (1971) Correlation between preoptic area unit activity and the cortical electroencephalogram: Difference between normal and castrated male rats. Electroencephalogr. Clin. Neurophysiol. 31: 223-230.

Phillis, J. W. (1980) Acetylcholine release from the cerebral cortex and its role in cortical arousal. Brain Res. 7: 378-389.

Price, J. L., and R. Stern (1983) Individual cells in the nucleus basalisdiagonal band complex have restricted axonal projections to the cerebral cortex in the rat. Brain Res. 269: 352-356.

Purpura, D. P. (1969) Interneuronal mechanisms in thalamically induced synchronizing and desynchronizing activities. In The Interneuron. V. E. Hall, ed., pp. 467-496, U. California Press, Berkeley, Los Angeles.

Rappelsberger, P., H. Pockberger, and H. Petsche (1981) The contribution of the cortical layers to the generation of the EEG: Field potential and current source density analyses in the rabbit's visual cortex. Electroencephalogr. Clin. Neurophysiol. 53: 254-269.
Reiner, P. B., K. Semba, H. C. Fibiger, and E. G. McGeer (1987) Physiological evidence for subpopulations of cortically projecting basal forebrain neurons in the anesthetized rat. Neuroscience 20:629636.

Rigdon, G. C., and J. H. Pirch (1986) Nucleus basalis involvement in conditioned neuronal responses in the rat frontal cortex. J. Neurosci. 6: 2535-2542.

Rossi, G. F., and A. Zanchetti (1957) The brain stem reticular formation. Arch. Ital. Biol. 95: 199-435.

Russchen, F. T., D. G. Amaral, and J. L. Price (1985) The afferent connections of the substantia innominata in the monkey, Macaca fascicularis. J. Comp. Neurol. 242: 1-27.

Ryan, L. J. (1984) Characterization of cortical spindles in DBA/2 and C57BL/6 inbred mice. Brain Res. Bull. 13: 549-558.

Sadowski, B., and V. G. Longo (1962) EEG and behavioral correlates of an instrumental reward conditioned response in rabbits. A physiological and pharmacological study. Electroencephalogr. Clin. Neurophysiol. 14: 465-476.

Saper, C. B. (1984) Organization of cerebral cortical afferent systems in the rat. I. Magnocellular basal nucleus. J. Comp. Neurol. 222:313342.

Schlag, J., and M. Waszak (1971) Electrophysiological properties of units of the thalamic reticular complex. Exp. Neurol. 32: 79-97.

Shute, C. C. D., and P. R. Lewis (1967) The ascending cholinergic reticular systems: Neocortical, olfactory and subcortical projections. Brain 90: 497-520.

Sillito, A. M., and J. A. Kemp (1983) Cholinergic modulation of the functional organization of the cat visual cortex. Brain Res. 289: 143155.

Singer, W. (1977) Control of thalamic transmission by corticofugal and ascending reticular pathways in the visual system. Physiol. Rev. 57: $386-420$.

Steriade, M. (1970) Ascending control of thalamic and cortical responsiveness. Int. Rev. Neurobiol. 12: 87-144.

Steriade, M., and M. Deschênes (1984) The thalamus as a neuronal oscillator. Brain Res. Rev. 8: 1-63.

Steriade, M., and P. Wyzinski (1972) Cortically elicited activities in thalamic reticularis neurons. Brain Res. 42: 514-520.

Steriade, M., A. Parent, and J. Hada (1984) Thalamic projections of nucleus reticularis thalami of cat: A study using retrograde transport of horseradish peroxidase and fluorescent tracers. J. Comp. Neurol. 229: 531-547.

Steriade, M., M. Deschênes, L. Domich, and C. Mulle (1985) Abolition of spindle oscillations in thalamic neurons disconnected from nucleus reticularis thalami. J. Neurophysiol. 54: 1473-1497.

Steriade, M., L. Domich, and G. Oakson (1986) Reticularis thalami revisited: Activity changes during shifts in states of vigilance. J. Neurosci. 6: 68-81.

Steriade, M., L. Domich, G. Oakson, and M. Deschênes (1987a) The deafferented reticular thalamic nucleus generates spindle rhythmicity. J. Neurophysiol. 57: 260-273.

Steriade, M., A. Parent, D. Pare, and Y. Smith (1987b) Cholinergic and noncholinergic neurons of cat basal forebrain project to reticular and mediodorsal thalamic nuclei. Brain Res. 408: 372-376.

Sterman, M. B., and C. D. Clemente (1962) Forebrain inhibitory mechanisms: Sleep patterns induced by forebrain stimulation in the behaving cat. Exp. Neurol. 6: 103-117.

Stewart, D. J., D. F. MacFabe, and C. H. Vanderwolf (1984) Cholinergic activation of the electrocorticogram: Role of substantia innominata and effects of atropine and quinuclidinyl benzylate. Brain Res. 322: 219-232.

Swartz, B. E., and C. D. Woody (1979) Correlated effects of acetylcholine and cyclic guanosine monophosphate on membrane properties of mammalian neocortical neurons. J. Neurobiol. 10:465-488.

Szerb, J. C. (1967) Cortical acetylcholine release and electroencephalographic arousal. J. Physiol. (Lond.) 192: 329-345.

Szymusiak, R., and D. McGinty (1986) Sleep-related neuronal discharge in the basal forebrain of cats. Brain Res. 370: 82-92.

Vanderwolf, C. H. (1975) Neocortical and hippocampal activation in relation to behavior: Effects of atropine, eserine, phenothiazines, and amphetamine. J. Comp. Physiol. Psychol. 88: 300-323.

Vanderwolf, C. H., and G. B. Baker (1986) Evidence that serotonin mediates non-cholinergic neocortical low voltage fast activity, noncholinergic hippocampal rhythmical slow activity and contributes to intelligent behavior. Brain Res. 374: 342-356.

Vanderwolf, C. H., and T. H. Robinson (1981) Reticulocortical ac- 
tivity and behavior: A critique of the arousal theory and a new synthesis. Behav. Brain Sci. 4: 459-514.

Vanderwolf, C. H., and D. J. Stewart (1986) Joint cholinergic-serotonergic control of neocortical and hippocampal electrical activity in relation to behavior: Effects of scopolamine, ditran, trifluoperazine and amphetamine. Physiol. Behav. 38: 57-65.

Villablanca, J. (1974) Role of the thalamus in sleep control. In Basic Sleep Mechanisms, P. Petre-Quadeus and J. Schlag, eds., pp. 51-81, Academic, New York.

Walker, A. E. (1938) The Primate Thalamus, U. Chicago Press, Chicago.
Whitehouse, P. J., D. L. Price, A. W. Clark, J. T. Coyle, and M. R. DeLong (1981) Alzheimer disease: Evidence for selective loss of cholinergic neurons in the nucleus basalis. Ann. Neurol. 10:122-126.

Wikler, A. (1952) Pharmacologic dissociation on behavior and EEG sleep patterns in dogs: Morphine, $N$-allylnormorphine and atropine. Proc. Soc. Exp. Biol. Med. 79: 261-265.

Wong, R. K. S., and D. A. Prince (1981) Afterpotential generation in hippocampal pyramidal cells. J. Neurophysiol. 45: 86-97. 